\title{
Ranking of Sustainable Medical Tourism Destinations in Iran: An Integrated Approach Using Fuzzy SWARA-PROMETHEE
}

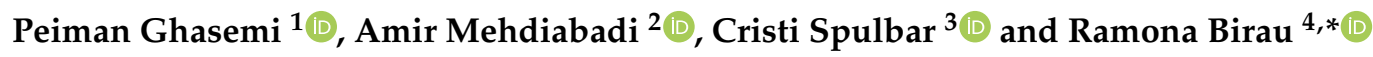 \\ 1 Department of Industrial Engineering, South Tehran Branch, Islamic Azad University, \\ Tehran 1584743311, Iran; st_p_ghasemi@azad.ac.ir \\ 2 Department of Management, South Tehran Branch, Islamic Azad University, Tehran 1584743311, Iran; \\ Amir.mehdiabadi@gmail.com \\ 3 Faculty of Economics and Business Administration, University of Craiova, 200585 Craiova, Romania; \\ cristi_spulbar@yahoo.com \\ 4 Faculty of Education Science, Law and Public Administration, Constantin Brancusi University of Targu Jiu, \\ 210135 Targu Jiu, Romania \\ * Correspondence: ramona.f.birau@gmail.com; Tel.: +40-767-970-777
}

check for

updates

Citation: Ghasemi, P.; Mehdiabadi, A.; Spulbar, C.; Birau, R. Ranking of Sustainable Medical Tourism

Destinations in Iran: An Integrated Approach Using Fuzzy SWARA-PROMETHEE. Sustainability 2021, 13, 683. https://doi.org/ $10.3390 /$ su13020683

Received: 9 December 2020 Accepted: 8 January 2021 Published: 12 January 2021

Publisher's Note: MDPI stays neutral with regard to jurisdictional clai$\mathrm{ms}$ in published maps and institutional affiliations.

Copyright: (C) 2021 by the authors. Licensee MDPI, Basel, Switzerland. This article is an open access article distributed under the terms and conditions of the Creative Commons Attribution (CC BY) license (https:// creativecommons.org/licenses/by/ $4.0 /)$.

\begin{abstract}
Today, medical tourism is one of the fastest growing sectors of the tourism industry around the world. Medical tourism can contribute to the sustainable development and economic dynamism of countries. Therefore, in this study, we prioritize the world's leading countries in medical tourism for Iranians. First, five main criteria and 20 sub-criteria were selected, which are the reasons for choosing a country as a medical tourism destination. In this paper a combined fuzzy SWARA-PROMETHEE approach was used to prioritize tourism destinations. The acronym PROMETHEE stands for Preference Ranking Organization Method for Enrichment Evaluation method and represents an useful MCDA (Multi-Criteria Decision Analysis) tool. On the other hand, SWARA acronym means Step-wise Weight Assessment Ratio Analysis. The criteria were weighted using the fuzzy SWARA approach. In the following, using the PROMETHEE approach, we prioritized eight countries as tourism destinations, then we identified criteria related to sustainability of medical tourism destinations and prioritized medical tourism destinations using these criteria as the contributions of this paper. The weights obtained for criteria "Abilities of skilled staff," "Applied medical equipment," "Marketing capability," "Type of service provided," and "Application of information and communications technology" were $0.176,0.232,0.108,0.395$, and 0.089 , respectively. The results show that medical tourism destination priorities for Iranians are India (Phi $=0.1396)$, Malaysia (Phi $=0.1128)$, Panama $(P h i=0.0976)$, Mexico $($ Phi $=0.0790)$, Singapore $($ Phi $=0.0096)$, Taiwan $(\mathrm{Phi}=-0.0442)$, Brazil $(\mathrm{Phi}=-0.1747)$, and Costa Rica $(\mathrm{Phi}=-0.2196)$, respectively. Negative Phi values indicate below average performance of those countries and positive Phi values indicate above average performance of those criteria. The results indicate that countries with negative Phi values should be strengthened relative to the improvement of some criteria.
\end{abstract}

Keywords: medical tourism; fuzzy SWARA; PROMETHEE; sustainable development; consumer; medical tourism destinations

\section{Introduction}

In recent decades, especially during the last 30 years in the application of new methods in the sub-sectors of the tourism industry, many efforts have been devoted to the sustainability of such activities. Until the late 1970s, tourism was introduced as a golden activity without drawbacks, and its positive consequences, especially its economic benefits, were always emphasized [1]. Numerous research findings and reports since the 1980s have confirmed the adverse environmental, social, and cultural consequences of tourism. In the 1990s, in line with the sustainable development paradigm, traditional approaches to tourism development were challenged, and with a simultaneous emphasis on the favor- 
able and unfavorable consequences of tourism, the movement from mass tourism to the approach to sustainable tourism development began [2].

Tourism as well as medical tourism can be sustainable if developed and managed, considering visitors/medical tourists and local communities/health care centers [3]. This can be achieved through community engagement, congestion management, reduction of seasonality, careful planning that respects the limits of capacity and the specificities of each destination, and product diversification [4,5]. Medical tourism is a type of tourism that happens in order to maintain, improve, and regain the physical and mental health of an individual in a period of more than $24 \mathrm{~h}$ and less than a year [6]. According to Connell (2013) medical tourism can be perceived as a vacation that entails traveling into foreign countries to access a wide range of health services [7]. Zarei et al. [8] defined medical tourism as an individual's travel for treatment (whether through medical intervention or the use of natural resources), rest, and maintaining physical health. This travel can be voluntarily or on the advice of a doctor [9].

Factors that include improving medical standards in developing countries, globalization and free trade in health care services [10], development of the Internet, and the emergence of communication companies that act as intermediaries between international patients and hospital networks and provide patients with easy access to information and prices, together with advanced technologies created with new care services have paved the way for the rapid growth of medical tourism [11]. In addition to the above, issues such as demographic changes in developed countries along with increasing problems in their health care systems such as long queues of patients, high costs of health services, and high rates of non-insurance coverage cause patients to travel from these countries to receive high quality and low cost health services [12].

Hadian et al. [13] defined medical tourism as a patient's travel to receive healing or disease aggravation preventive services outside the usual living environment for a minimum of one day and a maximum of one year, adding that the travel of healthy people who accompany the patient during this period should be considered a part of medical tourism. In general, medical tourism is any travel to promote health (for an individual or one of their family members) [14].

With global revenues of about USD 20 billion in 2005, it is one of the world's largest industries [15]. The medical tourism market included 19 million trips with a total value of USD 20 billion in 2005 [16]. According to the latest report, global medical tourism market was valued at approximately USD 65.5 billion in 2019 [17].

The increase in the number of uninsured people in Western countries as well as the increase in health care costs has led people to choose treatment abroad. Many countries are experiencing high growth in medical tourism [18]. As an interdisciplinary approach, Ganguli and Ebrahim (2017) revealed that medical tourism, which is a rapidly growing market, has been recognized by many countries as a potential sector for economic diversification [19]. The World Tourism Organization (WTO) specifically defines medical tourism as: Use of services that improve or enhance a person's health and well-being (using mineral water, weather, or medical interventions) in a place outside the person's residence that lasts longer than $24 \mathrm{~h}$. The global motto of health tourism is facilities and services at the level of the first or advanced countries of the world, and prices and costs at the level of developing countries and the third world [20].

The concept of health tourism was originally introduced by the International Union of Tourist Organizations (IUTO), which is the predecessor of UNWTO, in 1973. In other words, IUTO provided the following definition for health tourism, such as: "the provision of health facilities utilizing the natural resources of the country, in particular mineral water and climate" [21]. According to UNWTO/ETC's report on health tourism launched in 2018, health tourism "covers those types of tourism which have as a primary motivation the contribution to physical, mental and/or spiritual health through medical and wellnessbased activities" [22]. 
By 2025, it is predicted to grow to 500 million travels, or $10 \%$ of global tourism [23]. The number of medical tourists is also expected to increase exponentially [24]. For example, in Taiwan the number of medical travelers is expected to increase to 777,523 by 2025 [25]. In developed countries, each of the following issues can motivate people (demand side) to receive these services in other countries despite some problems such as lack of insurance coverage and the high cost of treatment [26]. Connell (2013) argued that familiarity with destinations represents a facilitator for potential medical tourists to select a particular country [7]. In addition, Heung et al. (2010) identified certain advantages of the medical tourism industry such as: increasing gross domestic product (GDP), improving medical services, and generating foreign exchange [6]. The following are some of the reasons for medical tourism:

Cost: The cost advantages of developed countries and new industrialized countries in the field of medical services have caused the emergence of this phenomenon [27]. The main direction of medical tourism can be from developed to developing countries or vice versa. People travel from developing countries to developed countries to use higher medical facilities and technologies. Also people travel from developed countries to developing countries due to the availability of cheaper medical services [28].

Growth in demand: In recent years, the demand for health care has increased in developed countries for reasons such as the aging population [29]. This issue lengthens the waiting time of patients.

Insurance: Due to the high cost of health insurance, a large group of people in developed countries do not have this insurance. Lack of insurance coverage for many cosmetic surgeries is another reason for the increase in medical tourists [19].

In addition, medical tourism in developing countries (supply side) has increased for the following reasons: 1. Globalization and liberalization of trade in the field of health services have caused the rapid growth of medical tourism [30]. 2. The growth and expansion of airlines has made it possible to use medical services in remote destinations [31]. 3. The Asian financial crisis has led governments to seek new sources of income [19]. 4. Favorable exchange rate changes in the global economy have made Asian countries suitable destinations for tourism [32]. 5. Rapid improvement of equipment [33].

The leading countries in the field of medical tourism are as follows [34]:

- Brazil: It is one of the oldest countries in medical tourism, which owes much of its fame to cosmetic surgery, but non-cosmetic surgery has little history in Brazil. The first hospital to be accredited by Joint Commission International (JCI) standards outside the United States was a hospital in Brazil that received the commission's certification.

- Costa Rica: Recently, Costa Rica has made great efforts in the field of medical tourism and has been one of the leaders of this industry since 2007. Costa Rica currently has three JCI-accredited hospitals, all three of which are in San José.

- India: One of the most important Asian countries in the field of medical tourism, with 22 hospitals, all of which have received JCI certification. Indian medical tourism is very popular in the world. Moreover, the main reason in attracting tourists to India is the relative cheapness of goods and services compared to other countries.

- Mexico: A very attractive destination for medical tourists, especially Americans. Americans living in the southern states bordering Mexico, such as New Mexico, Arizona, or Texas, go to Mexico almost routinely to receive cheap medical treatment.

- Panama: Amazing attractions, bilingual physicians, having international documents and standards, using the US dollar so the tourists do not need to convert their money. These reasons have made Panama one of the leaders in the international medical tourism industry.

- $\quad$ Singapore: This country has several JCI-accredited hospitals. Singapore's health standards are very high. According to the World Health Organization, in 2000 Singapore had the sixth best health care system in the world, and the first in Asia. 
- Taiwan: The government of Taiwan officially announced its intention to make its country a medical tourism center, and in 2007 the Taiwan Ministry of Health implemented a plan to raise the level of all medical services in the country.

- Malaysia: Malaysia provides guests with the best medical facilities in terms of cost. Most Malaysian medical tourists are from Southeast Asia because the cost difference is very high, and in addition, people in Muslim countries prefer to go to Malaysia for treatment because of the Malaysian Islamic culture.

Some other researchers argued that India, Indonesia, Malaysia, the Philippines, Singapore, Thailand and many other countries market themselves as major destinations for medical tourism [35]. Al-Talabani et al. (2019) suggested that countries like UAE, India, and the Philippines are leading, emerging major health care destinations, considering that health tourism represents at the moment a USD 100 billion global business, while this particular kind of tourism is currently experiencing an average growth rate of 25\% [4]. In addition, Lunt and Carrera (2011) highlighted the fact that medical tourism is an interdisciplinary trend, important in various disciplines, including inter-institutional cooperation [36].

Documentary and field studies in the field of health tourism in Iran show that, although health tourism in Iran has long been the focus of tourists and foreign patients entering the country and in recent years its organizational and legal management has begun, it is undergoing its first development and is facing the challenges that have arisen following the general conditions of the country in order to achieve its worthy position. These challenges are as follows:

A. Lack of a clear strategy and agency for health tourism at the international, national, and regional levels. Despite the introduction of tourism in the laws of the Islamic Republic of Iran as one of the pillars of economic development, the share and position of this sector in the economy is not fully understood and lacks a clear long-term strategy in dealing with domestic and foreign tourism applicants. Health tourism in Iran has more than 60 institutions and stakeholders, all of which, based on their organizational duties and powers in the field of tourism and health tourism, claim to participate in management and do not have a proper response.

B. Lack of a comprehensive health tourism system, definition and formulation of laws, policies and programs.

C. Lack of infrastructure, including communication infrastructure, training infrastructure for health tourism professionals, infrastructure of medical facilities and equipment, infrastructure for welfare and accommodation services of health tourists and their companions, legal infrastructure.

D. Lack of a codified and strong monitoring system; different quality of public and private centers, especially in the field of service quality; and weaknesses and shortcomings in the accreditation system.

E. Weakness in process management and design of standard service packages that can be provided to health tourists, such as: uncertain price of services, especially in the private sector; lack of a program and system for alternative, traditional and herbal medicine; and lack of medical tourism insurance, non-acceptance of medical tourism insurance coverage.

F. Lack of necessary private sector support from the government; lack of definition and explanation of the position of the private sector and the use of its many potentials; the tendency to governmentalize the issue despite previous unsuccessful experiences; and the weak role of private hospitals and trade unions.

G. Lack of integrated information management systems (M.I.S); lack and delay in establishing a system of registration, control, and statistics of health tourists; and lack of infrastructure and basic information of hospitals.

H. Lack of a clear marketing system, the presence of brokers and intermediaries along with providing inappropriate services at different prices, lack of marketing insti- 
tutions, lack of foreign marketing research, lack of overseas advertising system, insufficient knowledge of target markets, and poor marketing efforts.

The purposes of this research study are to select and rank the medical tourism destinations for the Iranian people. Therefore, at first, the sustainable criteria of medical tourism destinations are identified. In the following, using the fuzzy SWARA method, the weights of the identified criteria are determined based on the decision of experts. After determining the weights of the criteria, the medical tourist destinations are prioritized using the PROMETHEE method. The contributions of paper are as follows:

- Identify criteria related to sustainability in the subject of medical tourism destinations,

- Prioritize medical tourism destinations using a fuzzy SWARA-PROMETHEE approach,

- Investigating the strengths and weaknesses of medical tourism destinations based on sustainable factors,

- Application of the model to a real-world case study in Iran.

Therefore, the research questions are as follows:

1. What are the sustainable criteria for medical tourism purposes?

2. What are the medical tourism priorities of patients in Iran?

3. How to prioritize tourist destinations with a hybrid fuzzy SWARA-PROMETHEE method?

4. How does the prioritization of tourist destinations change with the change of sustainable criteria weights?

5. Which tourist medical destination country has performed poorly or strongly in terms of criteria?

This research is presented in five sections. In the first section, the introduction is mentioned. In the Section 2, the literature review is mentioned. This section is divided to medical tourism, medical tourism and sustainability, and analysis methods sub-sections. The materials and methods are presented in the Section 3. The results and discussions are described in the Section 4. Finally, conclusions are presented in the Section 5 of our research paper.

\section{Literature Review}

The literature review section is divided into two parts, including medical tourism and analysis methods.

\subsection{Medical Tourism}

Medical tourism is the most sensitive type of tourism among all types of tourism, because it is directly related to the life and health of the tourist. Although many countries in the world today offer health tourism services to earn money, the potential of a country in medical science and medical services, unlike recreational and sports tourism, is certainly not something that can only be achieved through construction and spending money. Therefore, identifying sustainable criteria for medical tourism destinations and prioritizing destinations can help patients to choose destinations tailored to their needs. Sustainable criteria cover all economic, social, and environmental dimensions. Therefore, identifying and prioritizing criteria can help tourism destinations to strengthen strengths and reduce their negative criteria [37].

Perkumiene et al. (2019) argued that sustainable medical tourism represents "an emergent and growing business worldwide, combining different and very specific purposes from pleasurable travel to sometimes-stressful services of health care" [3]. Lunt and Carrera (2011) suggested that medical tourism is related to the idea of a person traveling to a foreign country with the purpose of receiving medical procedures, with an emphasis on "clinical, surgical, and hospital provision" [36]. Kim et al. (2019) considered that medical tourism represents the phenomenon of traveling across national borders intentionally to access a variety of medical treatments, especially modern medical treatment [28]. Khan et al. (2020) suggested that international medical travel is defined as "the citizens of source country 
travel to foreign destination hospitals with the sole purpose of obtaining necessary medical procedures and treatment" [38].

Gan and Frederick (2011) revealed that medical tourism agencies (facilitators) actually include the organizations specializing in arranging suitable foreign hospitals and treatment, transportation, and lodging during recuperation [39]. Moreover, Hall (2011) revealed the existence of certain interrelationships between different areas of health and medical tourism, including wellness and well-being tourism, dental tourism, stem cell tourism, transplant tourism, abortion tourism, and xeno-tourism [40].

Some researchers [35] suggested that the concept of "medical tourists" includes those patients trying to avoid treatment delays and obtain timely access to health care. Kangas (2010) argued that terminology for medical travelers ranges from "medical tourists" to "medical exiles" [12]. Lee and $\mathrm{Li}$ (2019) argued that travel medicine is related to traveling to different countries for disease prevention, injury, immunology, infectious diseases, and vaccination, while medical travel is used for health inspections and plastic surgery, and involves medical treatment, rehabilitation, and self-care [41]. On the other hand, Wu and Guo (2014) mentioned that most people choose to take a getaway out of town in order to relax, improve their physical fitness, and engage in social activities, because of the natural environmental factors, including sound, temperature, humidity, atmospheric pressure, air, light, and lack of crowds [42].

The World Tourism Organization (UNWTO) defines the concept of sustainable tourism as: "Tourism that takes full account of its current and future economic, social and environmental impacts, addressing the needs of visitors, the industry, the environment and host communities" [21]. Spulbar et al. (2019) argued that, naturally, every country in the world needs to exploit its tourism potential in order to attract foreign capital for sustaining tourism and the hospitality industry [43]. To increase sustainable tourism it would be advisable to provide an increased level of customer satisfaction in order to facilitate the fulfillment of significant expectations for tourists, while raising their awareness about sustainability issues and promoting sustainable tourism practices among them [21].

The following Table 1 illustrates the difference between this work and the previous studies in literature. The literature review table is divided as follows:

1. Identify Criteria: In some articles, the criteria are identified by experts. In other articles, existing criteria or criteria of other researches are used.

2. Outranking method: A classical problem in the field of multiple-criteria decisionmaking (MCDM) is to build a preference relation on a set of multi-attributed alternatives based on preferences expressed on each attribute and "inter-attribute" information such as weights. Based on this preference relation (or, more generally, on various relations obtained following a robustness analysis) a recommendation is elaborated (e.g., exhibiting a subset likely to contain the "best" alternatives).

3. Fuzzy: Some studies consider data to be fuzzy to bring the problem closer to the real world, and others consider data Crisp.

4. Sustainability: Concurrent attention to social, economic, and environmental criteria is called sustainability.

5. Methods: These include a variety of mathematical or decision-making approaches.

6. Real case study: Some studies consider a real case study and others consider a numerical example. 
Table 1. Literature review.

\begin{tabular}{|c|c|c|c|c|c|c|}
\hline Paper & Identify Criteria & Out-Ranking Method & Fuzzy & Sustainability & Methods & Real Case Study \\
\hline Khan et al. (2020) [38] & & & & • & Conceptual framework & • \\
\hline Çavmak and Çavmak (2020) [44] & $\bullet$ & & & & AHP & $\bullet$ \\
\hline Farzin et al. (2019) [45] & & & & & ANFIS-SVR & $\bullet$ \\
\hline Nilashi et al. (2019) [46] & $\bullet$ & & $\bullet$ & & DEMATEL-F.TOPSIS & $\bullet$ \\
\hline Kim et al. (2019) [28] & • & & & & Conceptual framework & • \\
\hline Lou et al. (2019) [47] & $\bullet$ & & & $\bullet$ & AHP & $\bullet$ \\
\hline Y1ld1z and Khan (2019) [48] & $\bullet$ & & & & AHP & $\bullet$ \\
\hline Arif et al. (2019) [49] & & & & & TOPSIS & $\bullet$ \\
\hline Mayakul et al. (2018) [50] & $\bullet$ & & & $\bullet$ & Conceptual framework & $\bullet$ \\
\hline NajafiNasab et al. (2018) [51] & & & $\bullet$ & & SEM & $\bullet$ \\
\hline Rezaeenour et al. (2018) [52] & $\bullet$ & & & & AHP and TODIM & $\bullet$ \\
\hline Karami et al. (2017) [53] & $\bullet$ & & & $\bullet$ & AHP & $\bullet$ \\
\hline $\begin{array}{l}\text { MorovatiSharifabadi and } \\
\text { AsadianArdakani (2014) [54] }\end{array}$ & • & & & & TOPSIS-SEM & $\bullet$ \\
\hline Tsaur and Wang (2007) [55] & & & $\bullet$ & & F. AHP & $\bullet$ \\
\hline This paper & $\bullet$ & $\bullet$ & $\bullet$ & $\bullet$ & SWARA-PROMETHEE & $\bullet$ \\
\hline
\end{tabular}


Dreisbach et al. [56] discussed certain issues such as: cancer, tourism, and the relationship between tourism and health. In this study, a model was presented that could reflect and easily explain the need of these patients to go on vacation at different stages of the disease. During the course of the disease, people look for different ways of rehabilitation and comfort, such as alternative and complementary therapies and support groups. They may be able to access such help by going on vacation. Nilashi et al. [46] stated that medical tourists are guests of a hotel that devotes its time to a specific medical activity, so it is a product of tourism and the health sector. They considered the people who come for treatment as guests who devote only part of their time to a specific treatment and may use the rest of their time for other activities. In this study, tourism was considered along with the health sector, and the welfare facilities of medical tourism were considered, but the type of facilities was not mentioned.

Ahire et al. [57] examined the details of today's medical tourism creation. They compared prices in developing and developed countries, examined the medical tourism attractions and the available facilities, and stated that medical tourism has been created to meet the needs of a number of people, mostly from developed countries. The main centers of tourism are developing and mostly Asian countries, including India. Medical tourism in India accounts for $8.6 \%$ of India's GDP. Medical tourism includes the largest foreign financial transactions for these countries, as well. The medical tourism industry generated about USD 5 billion in revenue for India in 2018. This amount of GDP was the highest income from medical tourism in the world in 2018 [57].

Hall (2011) argued that the development of international medical tourism is demonstrated to have potentially significant implications for global public health [40].

\subsection{Medical Tourism and Sustainability}

Tourism is growing and developing very fast in the present era. Increasing demand in terms of quantity and quality can be considered the reason for this [3]. The laws and regulations of different countries indicate this [58]. However, it is very difficult to accurately define the types of tourism and the types of communications, information systems, and various services, other than from economic, social, and cultural perspectives [59]. Medical tourism is one of the most important and important types of tourism on which different countries cooperate bilaterally or multilaterally [3]. The economic benefits of medical tourism are many; governments, residents, and various businesses are beneficiaries of this type of tourism. It can also reduce the cost of transporting and exchanging information $[60,61]$.

Medical tourism is a kind of cultural confrontation between nations [62]; while they are considered tourists, they can travel long distances in order to receive a variety of medical services [7].

The medical tourist experiences the thrill of traveling and makes the best use of the potential services of the target country. Lower costs, quality of services, unavailability of internal facilities, long waiting queues, etc., are the main reasons for people traveling for medical tourism $[63,64]$. Medical tourism will involve both the private and public sectors [65]. The important point is to correctly and accurately identify the pillars of tourism development in this chain [66].

In other words, by identifying lifestyles, types of luxury, and globalization, and moving toward sustainability and types of consumer behavior, medical tourism can contribute to sustainable development [67]. Sustainable medical tourism as a multifaceted phenomenon has several definitions [66,68,69]. The focus of tourists on quality products and services is in fact a requirement to meet their physical, social, and spiritual needs through the development of sustainable tourism and the provision of desirable services [70]. The significant increase in the number of medical tourists in recent years is directly and indirectly determined by environmental indicators on human health and well-being [71].

The results of numerous researches of scientists show that there are two motivations in medical tourists to travel: the first is related to the economic situation, political climate, and 
hospitality standards, and the second is related to medical service providers in the target country, which includes costs, accreditation standards, and service quality, including professional qualifications [3]. In fact, the development of sustainable tourism is to strengthen the opportunities ahead while maintaining the needs of tourists [3]. All resources and facilities must be mobilized to maintain cultural interaction, environmental, economic, and social and information sharing needs. In many scientific sources, the subject of sustainability refers to: 1 -ideal natural resources, 2 -respect for the comprehensive cultural and social originality of the host, 3 -ensuring positive and sustainable economic performance, 4 -providing social and economic benefits for all stakeholders, 5-participation of all stakeholders, 6-satisfaction of tourists [30,72].

In some sources, providing high quality services is the key to sustainable competitive advantage [73]. The need to pay attention to the sustainable development of medical tourism along with the positive economic impact on the host community and surrounding areas as well as the access of millions of people to a variety of affordable medical services can create strong social impacts [3]. Tourists' experiences of traveling to countries targeted for medical tourism can be valuable. Then, creating a chain of cooperation between governments to strengthen the opportunities for medical tourism and introduce different services to each other can lead to sustainable economic, social, environmental, and cultural development.

\subsection{Iranians and Medical Trips}

Despite the various facilities inside the country, Iranians in some cases prefer to travel to different countries to do the following:

- Medical Tourism: This type of trip is done to treat the disease, perform surgery, or check the health of the tourist in the clinics and hospitals of the destination country. The existence of experienced physicians, medical history, medical and supervisory infrastructures, standard hospitals and clinics, complete and up-to-date medical equipment, as well as laws and medical supervision are among the important medical infrastructures of the destination country.

- Curative Tourism: Travel to countries with natural healing resources such as hot springs, salt lakes, mud baths, clean environment, and bright sunshine is included in the nature tourism. On this type of trip, skin, respiratory, rheumatology, and muscle patients travel to these areas for medical massage, herbal baths, as well as to recover from treatment and surgery.

- Wellness Tourism: In health tourism, the tourist travels to get rid of the stresses of daily life and seek peace. Usually, these tourists do not have a specific physical illness and are more interested in enjoying the healing nature and avoiding the hustle and bustle of urban life. Health tourists travel for a variety of services, including fitness and exercise, beauty treatments, healthy eating and weight management, relaxation and stress reduction, meditation, yoga, and health-related training.

\subsection{Benefits and Reasons for Choosing Health Tourism as a Treatment}

There are many reasons why Iranians go abroad for medical treatment, the most important of which are:

- Disappointment with treatment in their home country,

- Lack of access to medical care at an appropriate time and cost,

- Insufficient insurance and income to cover the costs of local health services,

- High quality medical care in developing countries,

- Variety of treatment options,

- Desire to receive medical care away from a monotonous and permanent place (escapism),

- Lack of waiting list,

- Growing popularity for overseas medical services,

- Access to the latest technologies,

- Existence of oppressive sanctions and access to all kinds of drugs. 


\subsection{Analysis Methods}

\subsubsection{Analytic Hierarchy Process (AHP) and Analytic Network Process (ANP)}

Çavmak and Çavmak (2020) identified and prioritized 23 medical tourism barriers in Turkey. They divided the barriers into five general categories and prioritized them with an AHP approach. The criteria considered included the following: target brand, social issue, tour holder, target market, tourism product, and communication channels [44]. Lou et al. (2019) presented the risk factors in the sustainable development of healthy cities using the AHP approach. The criteria considered included the following: "safety," "sustainable ecology," "vitality and health," "culture friendly" and "convenience and prosperity." The results indicated that safety is selected as the most important criterion [47]. Ylldiz and Khan (2019) investigated the aspects that are considered relatively more important by medical tourists from the Arab region in Turkey. Two indicators of performance and importance were considered to evaluate the proposed criteria with the collected questionnaire. The results indicated the appropriate performance of the AHP approach to prioritize options [48]. Rezaeenour et al. (2018) in Iran evaluated the quality of hospital services, with the aim of developing medical tourism, with a combined approach to fuzzy AHP and TODIM [52]. Moreover, TODIM is the Portuguese abbreviation for Interactive and Multi Criteria Decision Making. Roy et al. (2017) in an attractive study evaluated and selected medical tourism sites based on the R-AHP and R-MABAC approach [74]. The acronym MABAC stands for Multi-Attributive Border Approximation Area Comparison. In their study, Görener and Taşçı (2016) evaluated medical tourism strategies based on the SWOT framework with a combined AHP and MOORA approach [75]. The acronym SWOT is based on the following key elements: Strengths, Weaknesses, Opportunities, and Threats, while MOORA framework stands for Multi-Objective Optimization by Ratio Analysis. In a study, Levary (2011) ranked medical tourism destinations by AHP [57]. Bies and Zacharia (2007) addressed the issue of outsourcing surgery (Outsourcing Surgical Care) in medical tourism using the ANP approach [76].

\subsubsection{TOPSIS}

Arif et al. (2019) investigated medical tourism destination priority in Batu City. They presented the 6AsTD framework and TOPSIS method as a combination concept to rank medical tourism destinations. TOPSIS represents one of the MCDM (Multiple Criteria Decision Making) methods with a large applicability. The acronym TOPSIS stands for Technique for Order Performance by Similarity to Ideal Solution. The 6AsTD method has six criteria that reflect successful medical tourism destinations. The research results indicated the appropriate performance of the proposed combined approach [49]. Rezaee (2019) investigated the location of medical tourism destinations in Charmahal and Bakhtiaree Province. They used GIS model for locating destinations and used the TOPSIS method for ranking them. The results showed that Chelgerd was selected as the best tourist destination [77]. Nilashi et al. (2019) presented factors that influenced medical tourism in Malaysia. They considered environmental, human, and technological factors. The data were collected from hotel managers. They used fuzzy TOPSIS and DEMATEL methods for ranking alternatives. On the other hand, the acronym DEMATEL stands for Decision making trial and evaluation laboratory. Finally, the results showed that technological factors are the most important factors [46].

\subsubsection{DEMATEL}

Farzin et al. (2019) used fuzzy Delphi and fuzzy DEMATEL to predict the demand for medical tourism in Tehran (Iran) [45]. Modiri et al. (2017) in their research selected medical tourism strategies based on the SWOT framework with a combined approach of fuzzy DEMATEL, fuzzy ANP, and fuzzy VIKOR [78]. The acronym VIKOR is in Serbian language and stands for vlseKriterijumska Optimizacija I Kompromisno Resenje and also represents a multi-criteria decision making (MCDM) method. Taghvaei and Goodarzi (2016) also prioritized medical tourism strategies with a combination of fuzzy DEMATEL, fuzzy ANP 
and AHP [79]. Chen (2012) used the DEMATEL approach to develop medical tourism in Taiwan [80].

\subsubsection{VIKOR}

Taghizadeh Yazdi and Barazandeh (2016) evaluated and prioritized the barriers to the development of health tourism in Iran with a fuzzy VIKOR approach [81]. Hung et al. (2014) improved medical screening services with a combined DEMATEL-ANP (DANP) and VIKOR approach [82].

\subsubsection{Other Techniques}

Abouhashem Abadi et al. (2018) evaluated medical tourism strategies in their research study based on the best-worst method (BWM) approach [83]. Although Iran has been very successful in providing medical services in recent years, there is not a global priority for medical tourism. Therefore, in this research, with a fuzzy approach, we seek to identify the medical tourism criteria and prioritize the most important countries regarding medical tourism for the Iranians.

\section{Materials and Methods}

The main objective of this research study was to select and rank the medical tourism destinations for the Iranian people. Questionnaires on the motivation of individuals to choose medical tourism destinations were distributed and collected during 2019. According to the population size, which was 750 people, the sample size was calculated as 256 people, based on the Cochran method. The statistical population included people who have traveled as medical tourists from Iran to other countries. This statistic was based on information from the Ministry of Health of Iran from 2019.The analysis was performed in two parts. In the first part, fuzzy SWARA was used to weigh the specified criteria and sub-criteria; and in the second part, the PROMETHEE method was used to prioritize eight countries with the highest level of medical tourism, selected based on the indicators and opinions of experts. The executive framework of the research is presented in the following Figure 1.

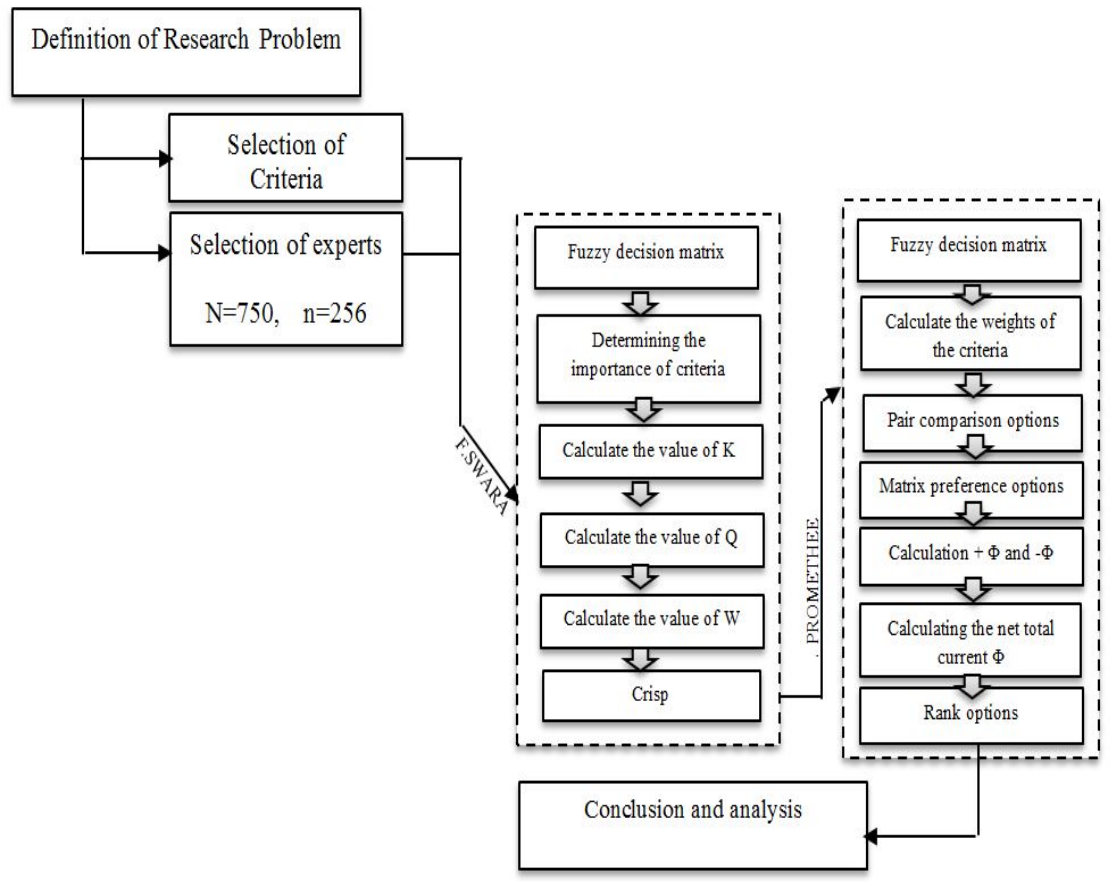

Figure 1. The executive framework of the research. Source: Author's own contribution. 
There is a limit to the use of the PROMETHEE technique to compensate for the weakness of one criterion or the strength of another. Therefore, an ideal alternative should obtain the minimum of all criteria. In addition, the PROMETHEE method is easily able to use criteria with different measurement scales (no need to normalize the scale of the criteria) and defines the criteria for the six separate preference functions information. Therefore, in multi-criteria decision-making such as PROMETHEE, which usually has different measurement criteria, there was a strong point for decision-making.

The reasons for using SWARA approach were as follows: Firstly, SWARA's approach is different from other similar methods, such as ANP and AHP. SWARA gives the chance to decision makers to select their priority based on the current situation of alternatives. Secondly, the role of the experts is very important in this approach. At the end, it should be added that SWARA has the advantage of a more logical calculation of weights and relative importance of criteria [84].

\subsection{Fuzzy SWARA}

The use of fuzzy numbers in analysis is due to uncertainty in decisions [85]. The use of fuzzy SWARA is less common in decision-making literature [86]. Some researchers have been working on this in recent years [87,88]. Crisp SWARA, developed by Keršuliene et al. [89], is inadequate to handle uncertainty, so the fuzzy extension of this method was developed. The reason for using the fuzzy SWARA approach was the inherent uncertainty of deciding on medical tourism destinations. Also, due to the qualitative nature of most of the criteria and the ease of collecting the opinions of decision makers, a SWARA fuzzy approach was used. Using a fuzzy approach brings the results closer to the real world.

The process of determining the relative weight of the criteria using the SWARA method with the following steps can be shown in detail [90]:

We arranged the criteria in descending order.

According to the Table 2, we determined the relative importance of factor $j$ compared to the previous factor $(j-1)$, which was of higher importance.

Table 2. Fuzzy and linguistic values [91].

\begin{tabular}{cc}
\hline Linguistic Scale & Response Scale \\
\hline Equally Important & $(1,1,1)$ \\
\hline Moderately Less Important & $(2 / 3,1,3 / 2)$ \\
\hline Less Important & $(2 / 5,1 / 2,2 / 3)$ \\
\hline Very Less Important & $(2 / 7,1 / 3,2 / 5)$ \\
\hline Much Less Important & $(2 / 9,1 / 4,2 / 7)$ \\
\hline
\end{tabular}

Source: Author's own contribution.

1. Calculate the value of $\tilde{k}_{j}$ using Equation (1). It should be noted that the fuzzy parameters are shown with the symbol $\sim$.

$$
\tilde{k}_{j}=\left\{\begin{array}{c}
\tilde{1} j=1 \\
\tilde{S}_{j}+1 j>1
\end{array}\right\}
$$

where $\tilde{k}_{j}$ is the value of the coefficient of comparative importance.

2. Calculate the value of $\tilde{q}_{j}$ using Equation (2):

$$
\tilde{q}_{j}=\left\{\begin{array}{c}
1 j=1 \\
\tilde{k}_{j-1} j>1 \\
\widetilde{k}_{j} j
\end{array}\right\}
$$


where $\tilde{q}_{j}$ is value of the fuzzy weights of the criteria.

3. Calculate the weight of the criteria using Equation (3),

where $n$ is the number of criteria and $\tilde{W}_{j}$ is the weight of the criterion $j$ :

$$
\tilde{W}_{j}=\frac{\tilde{q}_{j}}{\sum_{k=1}^{n} \tilde{q}_{k}} .
$$

\subsection{PROMETHEE}

The PROMETHEE method uses outranking method relation between alternatives to solve problems that have a finite action and need to be sorted considering different criteria and different units [92,93]. Unlike other ranking methods, which apply the same ranking scale and preference function (PF) in the ranking process, PROMETHEE usually uses different preference functions to define different decision attributes according to their different characteristic $[94,95]$. The procedure of PROMETHEE is constituted by four steps:

Calculating the deviations based on comparison between two alternatives with respect to $\mathrm{j}$ the criterion using Equation (4):

$$
d_{j}(a, b)=f_{j}(\mathrm{a})-f_{j}(\mathrm{~b}) \quad j=1,2, \ldots, k
$$

where $j$ denotes the $j$ th criterion $k$ stands for the finite number of criteria. $d_{j}(a, b)$ is the difference between the evaluations of two actions (a) and $\left.f_{j}(\mathrm{~b})\right)$ for criterion.

Applying the preference function using Equations (5) and (6):

$$
\begin{gathered}
P_{j}(a, b)=F_{j}\left[d_{j}(a, b)\right] j=1,2, \ldots, k \\
0 \leq P_{j} \leq 1 \quad j=1,2, \ldots, k
\end{gathered}
$$

where $P_{j}(a, b)$ expresses the preference for alternative a with regard to alternative $b$ on the jth criterion.

Calculating a global preference index. The overall multi-criteria preference list $\pi(a, b)$ is denoted as Equation (7):

$$
\pi(a, b)=\sum_{j=1}^{k} W_{j} P_{j}(a, b) j=1,2, \ldots, k
$$

where $w_{j}$ represents the weight of the criterion $j$.

Calculating the outranking flows. The outgoing flow $p h i^{+}$, which defines the outranking of alternative a (how a dominates all the other alternatives), and the incoming flow phi $i^{-}$, which indicates the outranked character of alternative a (how a is dominated by all the other alternatives), can be represented as follows [96]:

$$
\begin{aligned}
& p h i^{+(a)}=\sum_{x \in A} \pi(x, a) \\
& p h i^{-(a)}=\sum_{x \in A} \pi(a, x)
\end{aligned}
$$

where a denotes the alternative set and $x$ represents all alternatives except alternative $a$.

The net flow phi (a), which is defined by Equation (10), expresses the overall preferred degree of alternative a. Higher value of $p h i(a)$ means a better performance of alternative a.

$$
\text { phi(a)phi. }
$$




\section{Results and Discussion}

After conducting the research steps, the specified criteria are presented in Table 3. To select these criteria, the opinions of five experts with more than 20 years of experience in the field of medical tourism were used. These experts were among the most experienced surgeons in the country who have been working in the field of medical tourism in various countries for many years. These people were among the most experienced and specialized university people in the field of medical tourism in the country. These experts were selected only to select criteria and the questionnaire was filled by medical tourists.

Table 3 shows the criteria used to select a medical tourism destination.

The options (alternatives) considered by experts were Brazil, Costa Rica, India, Mexico, Panama, Singapore, Taiwan and Malaysia. The reasons were the high incomes and foreign exchange earnings that the medical tourism of these countries had, and many governments are trying to strengthen this industry in their country.

The global and local weights of the considered criteria and sub-criteria obtained by fuzzy SWARA approach are shown in Table 4:

Table 5 shows the output results of Visual PROMETHEE software. The official site and the tutorial version of the software can be downloaded from http:/ / www.prometheegaia.net. This table shows the values of Phi (a), $\operatorname{Phi}(a)^{+}$and $\operatorname{Phi}(a)^{-}$. The value of Phi (a) is equal to the difference between the values of $\operatorname{Phi}(a)^{+}$and $\mathrm{Phi}(a)^{-}$.

The GAIA plane is the principal plane obtained by applying a principal components analysis to the set of actions in this space. Moreover, a GAIA plane represents a focal-plane assembly and has a major applicability in space applications.

In the GAIA plane, the following relationships hold:

1. The longer the axis of a criterion is, higher the distinguishing power of that criterion will be.

2. The criteria that have similar preferences are shown by almost parallel axes.

3. The criteria that have conflicting preferences are shown in opposite directions.

4. The criteria that do not communicate with each other (in terms of the preference) are perpendicular to each other.

5. The similar actions are shown by points close to each other.

6. Suitable actions on a criterion are shown by points in the direction of the given criteria. 
Table 3. Identified sustainable criteria for choosing a medical tourism destination.

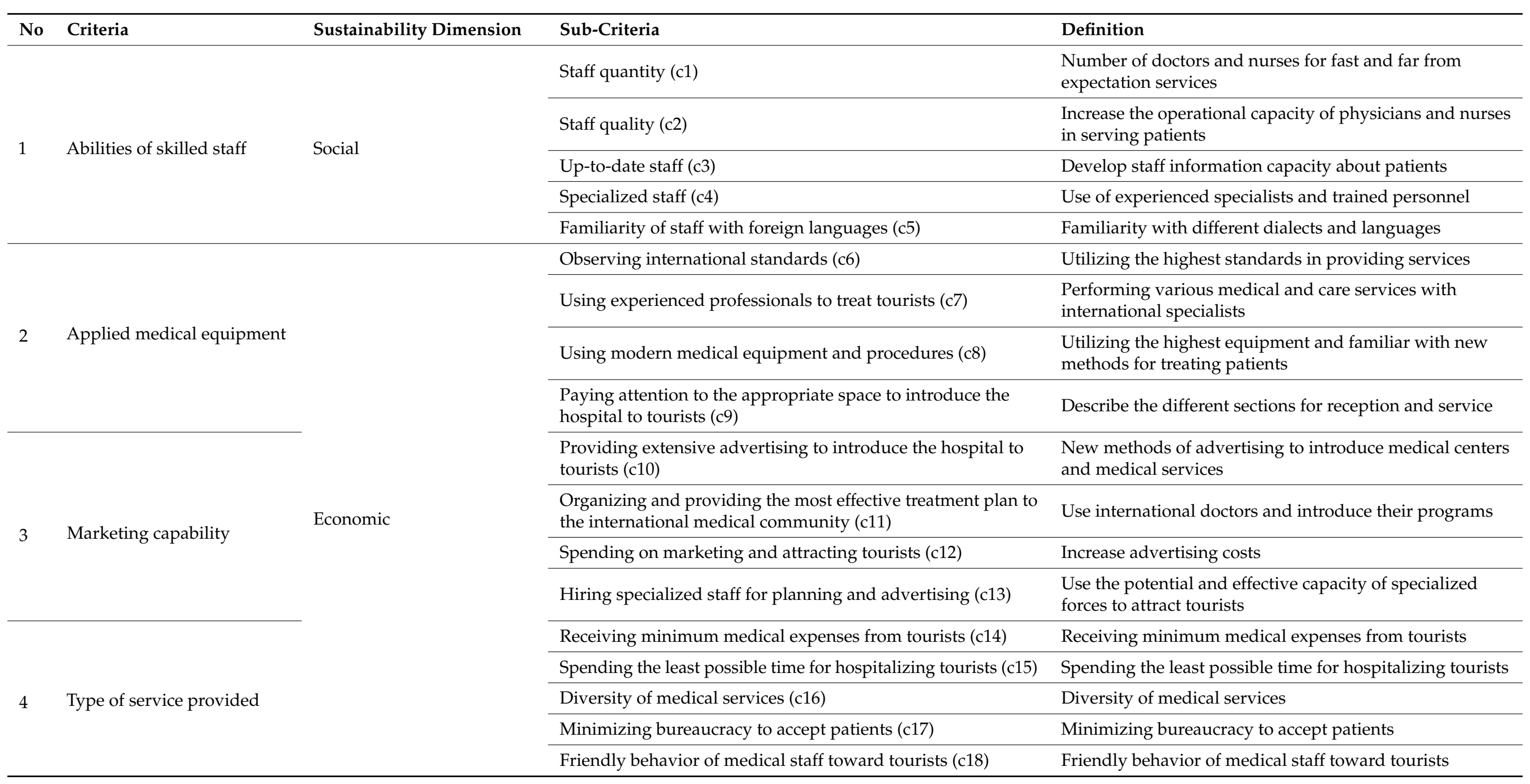


Table 3. Cont.

\section{No Criteria}

Application of information

5 and communications

technology
Sustainability Dimension

\section{Sub-Criteria}

Having a special website to introduce the diversity and

environmental-therapeutic attractions of the destination

country (c19)

Environmental

Coordinating the patient's medical information with the

hospital of the country of origin to inform about the types of

special environmental attractions, taking into account the

physical and mental conditions (c20)

\section{Definition}

A specialized and special website to introduce all kinds of medical tourism attractions with good and easy access and transparent information

Identify the condition and situation of the patient in the country of origin and check his or her opinion and interest in having all kinds of facilities in the destination country 
Table 4. The criteria and sub-criteria obtained by fuzzy SWARA.

\begin{tabular}{|c|c|c|c|c|c|c|c|c|}
\hline Main Criteria & $W_{j}$ & Sub-Criteria & $b_{j}$ & $k_{j}$ & $q_{j}$ & $W_{j}$ & Local Weight & Global Weight \\
\hline \multirow{5}{*}{ Abilities of skilled staff } & \multirow{5}{*}{0.176} & c2 & & $(1,1,1)$ & $(1,1,1)$ & $(0.360,0.466,0.420)$ & 0.415 & 0.073 \\
\hline & & c3 & $(0.4,0.5,0.667)$ & $(1.4,1.5,1.667)$ & $(0.714,0.666,0.599)$ & $(0.257,0.310,0.252)$ & 0.274 & 0.0482 \\
\hline & & c4 & $(0.23,1.5,0.465)$ & $(1.23,2.5,1.465)$ & $(0.580,0.266,0.408)$ & $(0.209,0.124,0.171)$ & 0.169 & 0.0297 \\
\hline & & c1 & $(1,1,1)$ & $(2,2,2)$ & $(0.29,0.133,0.204)$ & $(0.104,0.062,0.085)$ & 0.084 & 0.0147 \\
\hline & & c5 & $(0.540,0.650,0.23)$ & $(1.54,1.65,1.23)$ & $(0.188,0.08,0.165)$ & $(0.067,0.037,0.069)$ & 0.058 & 0.0102 \\
\hline \multirow{4}{*}{ Applied medical equipment } & \multirow{4}{*}{0.232} & c7 & & $(1,1,1)$ & $(1,1,1)$ & $(0.429,0.579,0.456)$ & 0.489 & 0.1134 \\
\hline & & c8 & $(0.53,1.74,0.37)$ & $(1.53,2.74,1.37)$ & $(0.653,0.364,0.729)$ & $(0.280,0.210,0.332)$ & 0.273 & 0.0633 \\
\hline & & c6 & $(0.444,0.5,1.36)$ & $(1.444,1.5,2.36)$ & $(0.452,0.242,0.308)$ & $(0.193,0.14,0.14)$ & 0.159 & 0.0368 \\
\hline & & c9 & $(1,1,1)$ & $(2,2,2)$ & $(0.226,0.121,0.154)$ & $(0.096,0.070,0.070)$ & 0.079 & 0.0183 \\
\hline \multirow{3}{*}{ Marketing capability } & \multirow{3}{*}{0.108} & c11 & & $(1,1,1)$ & $(1,1,1)$ & $(0.450,0.496,0.537)$ & 0.495 & 0.0534 \\
\hline & & $\mathrm{c} 12$ & $(0.5,0.66,1.12)$ & $(1.5,1.66,2.12)$ & $(0.666,0.602,0.471)$ & $(0.299,0.298,0.252)$ & 0.284 & 0.0306 \\
\hline & & c13 & $(1.04,1.5,1)$ & $(2.04,2.5,2)$ & $(0.326,0.24,0.235)$ & $(0.146,0.119,0.126)$ & 0.131 & 0.0141 \\
\hline \multirow{5}{*}{ Type of service provided } & \multirow{5}{*}{0.395} & c14 & & $(1,1,1)$ & $(1,1,1)$ & $(0.459,0.503,0.52)$ & 0.495 & 0.1955 \\
\hline & & c16 & $(1,1,1)$ & $(2,2,2)$ & $(0.5,0.5,0.5)$ & $(0.229,0.251,0.26)$ & 0.247 & 0.0975 \\
\hline & & c15 & $(0.63,1.2,1)$ & $(1.63,2,2)$ & $(0.306,0.25,0.25)$ & $(0.14,0.125,0.13)$ & 0.132 & 0.0521 \\
\hline & & c17 & $(0.444,0.76,0.1 .32)$ & $(1.444,1.76,2.32)$ & $(0.211,0.142,0.107)$ & $(0.097,0.071,0.055)$ & 0.075 & 0.0296 \\
\hline & & c18 & $(0.333,0.5,0.666)$ & $(1.333,1.5,1.666)$ & $(0.158,0.094,0.064)$ & $(0.072,0.047,0.033)$ & 0.051 & 0.0201 \\
\hline \multirow{2}{*}{$\begin{array}{l}\text { Application of information and } \\
\text { communications technology }\end{array}$} & \multirow{2}{*}{0.089} & c19 & & $(1,1,1)$ & $(1,1,1)$ & $(0.666,0.666,0.666)$ & 0.666 & 0.0592 \\
\hline & & $\mathrm{c} 20$ & $(1,1,1)$ & $(2,2,2)$ & $(0.5,0.5,0.5)$ & $(0.333,0.333,0.333)$ & 0.334 & 0.0297 \\
\hline
\end{tabular}


Table 5. Results of PROMETHEE calculation.

\begin{tabular}{cccl}
\hline Actions & Phi & Phi+ & Phi- \\
\hline India & 0.1396 & 0.5213 & 0.3818 \\
\hline Malaysia & 0.1128 & 0.4905 & 0.3778 \\
\hline Panama & 0.0976 & 0.4971 & 0.3995 \\
\hline Mexico & 0.0790 & 0.4854 & 0.4064 \\
\hline Singapore & 0.0096 & 0.4566 & 0.4470 \\
\hline Taiwan & -0.0442 & 0.4188 & 0.4630 \\
\hline Brazil & -0.1747 & 0.3629 & 0.5375 \\
\hline Costa Rica & -0.2196 & 0.3405 & 0.5601 \\
\hline Source: Author's own contribution. & & &
\end{tabular}

Table 6 shows the global decision matrix obtained by the experts' opinions.

Table 6. Global decision matrix.

\begin{tabular}{cccccccccccccccccccccc}
\hline A/C & C1 & C2 & C3 & C4 & C5 & C6 & C7 & C8 & C9 & C10 & C11 & C12 & C13 & C14 & C15 & C16 & C17 & C18 & C19 & C20 \\
\hline A1 & Vb & A & A & A & A & G & A & B & A & G & Vg & Vg & Vg & A & B & G & G & A & Vb & Vg \\
\hline A2 & Vg & A & A & Vg & Vg & G & A & Vg & B & B & A & Vg & G & G & G & G & B & B & G & B \\
\hline A3 & G & G & A & G & G & A & A & Vb & B & B & Vg & Vb & A & Vg & G & G & Vg & B & G & G \\
\hline A4 & B & A & A & A & A & B & G & Vb & Vg & B & A & A & Vg & Vb & Vb & A & Vg & G & G & B \\
\hline A5 & A & G & A & Vg & A & G & B & A & Vg & Vg & G & B & Vg & G & B & Vg & G & Vg & G & Vg \\
\hline A6 & G & A & G & G & A & B & B & Vg & Vb & Vg & A & B & Vb & A & G & B & A & G & B & Vb \\
\hline A7 & A & A & G & A & A & A & A & Vg & Vb & A & Vb & B & Vb & G & Vg & B & B & A & A & Vg \\
\hline A8 & G & A & G & B & A & A & A & Vb & Vg & A & B & G & Vb & G & Vb & B & A & B & B & Vb \\
\hline
\end{tabular}

Source: Author's own contribution. Note: Vb: Very bad, B: Bad, A: Average, G: Good, Vg: Very good, A1: Panama, A2: Malaysia, A3: Mexico, A4: Singapore, A5: India, A6: Taiwan, A7: Brazil, A8: Costa Rica.

Table 7 shows the numerical values of the linguistic terms.

Table 7. Numerical values of the linguistic terms.

\begin{tabular}{cc}
\hline Linguistic Term & Value \\
\hline Vb & 9 \\
B & 7 \\
A & 5 \\
G & 3 \\
Vg & 1 \\
\hline
\end{tabular}

Source: Author's own contribution.

Table 8 presents the type of optimization of the sub-criteria and the preference functions as follows:

Table 8. Type of optimization of the sub-criteria and the preference functions.

\begin{tabular}{lllllllllllllllllllll}
\hline A/C & c1 & c2 & c3 & c4 & c5 & c6 & c7 & c8 & c9 & c10 & c11 & c12 & c13 & c14 & c15 & c16 & c17 & c18 & c19 & c20 \\
\hline Type & Max & Max & Max & Max & Max & Max & Max & Max & Max & Max & Max & Max & Max & Min & Min & Max & Min & Max & Max & Max \\
\hline PF & Lin & $\mathrm{U}$ & $\mathrm{U}$ & $\mathrm{U}$ & $\mathrm{U}$ & $\mathrm{U}$ & $\mathrm{U}$ & $\mathrm{U}$ & $\mathrm{U}$ & $\mathrm{U}$ & $\mathrm{U}$ & $\mathrm{U}$ & $\mathrm{U}$ & $\mathrm{Us}$ & $\mathrm{Us}$ & $\mathrm{U}$ & $\mathrm{U}$ & $\mathrm{U}$ & $\mathrm{U}$ & $\mathrm{U}$ \\
\hline
\end{tabular}


According to Table 4, the GAIA plane is shown in Figure 2. This figure is the output of the Visual PROMETHEE software. Due to the multidimensionality of the GAIA plane, the left-side plane shows the $\mathrm{U}-\mathrm{V}$ dimension, and the right-side plane shows the $\mathrm{U}-\mathrm{W}$ dimension (Figure 2). The red axis is called the decision brain and shows the preference of the decision makers. As can be seen in the left-side plane, India is closer to the criteria than other countries, and Costa Rica and Brazil are the farthest. According to this plane, criteria c8 and c15 are in the same direction and also, criteria c7 and c9 are in the same direction. This indicates that these criteria have similar objectives. The proximity of $\mathrm{c} 6, \mathrm{c} 18$ and $\mathrm{c} 10$ to India indicates that it performed well in terms of these criteria.

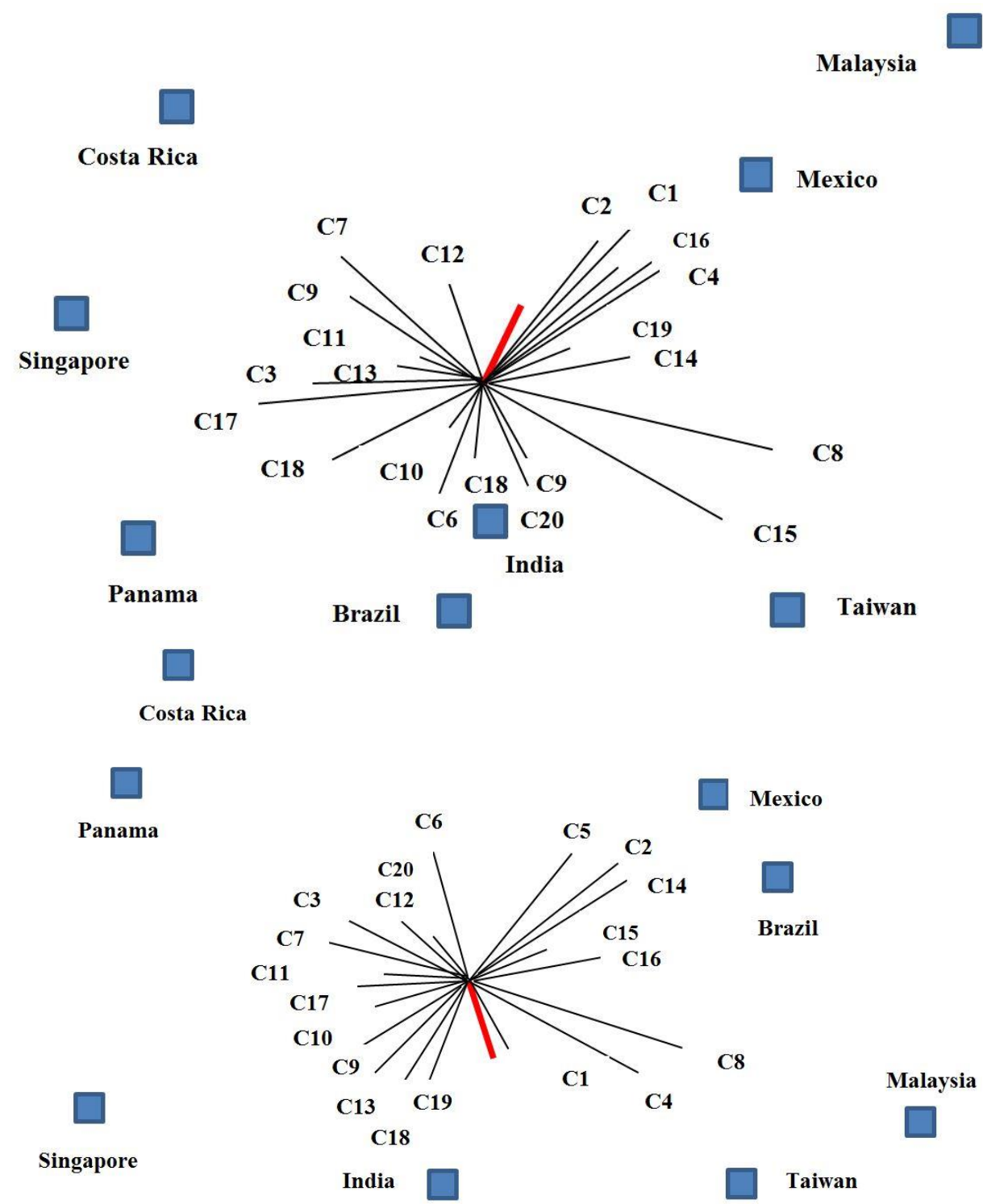

Figure 2. GAIA plane analysis. Source: Author's own contribution.

The results of the right-side plane indicate that the decision brain is inclined toward India, and according to this plane, India was selected as option 1. Taiwan also performed well in terms of $c 8$ and $c 4$, while it performed poorly in terms of $c 3$ and $c 7$. The gap between India and Costa Rica in this plane shows the difference between the criteria of these two countries and also their ranking.

Table 9 shows the ranking of medical tourism destinations. This table is the output of the Visual PROMETHEE software and the PROMETHEE V method. As can be seen in the PROMETHEE V results, Costa Rica was the last option for a medical tourism destination 
and Brazil was the seventh option. Taiwan and Singapore also ranked sixth and fifth, respectively. So the global ranking was India, Malaysia, Panama, Mexico, Singapore, Taiwan, Brazil, and Costa Rica, respectively. The optimal results of the objective function of the PROMETHEE V approach were $0.6453(0.2522+0.2982+0.0636+0.0312)$.

Table 9. PROMETHEE V global ranking.

\begin{tabular}{ccc}
\hline Actions & Net Flow & Optimal \\
\hline Malaysia & 0.2522 & yes \\
\hline Taiwan & -0.0726 & no \\
\hline Brazil & -0.3157 & no \\
\hline Mexico & -0.0619 & no \\
\hline Panama & 0.2982 & yes \\
\hline India & 0.0636 & yes \\
\hline Costa Rica & -0.1951 & no \\
\hline Singapore & 0.0312 & yes \\
\hline Total & & \\
\hline
\end{tabular}

Source: Author's own contribution.

From the PROMETHEE 2 method, which is a complete ranking, we got a complete summary of the options ranking. But PROMETHEE $\mathrm{V}$ also includes restrictions on criteria; for example, if we have a measure called cost or budget, we can create a limit on this criterion.

Figure 3 shows the GAIA web plane. This figure is the output of the Visual PROMETHEE software. This plane shows the importance and quality of a criterion based on the desired option. The left-side plane shows the criteria for India. According to this plane, India performed well in terms of "paying attention to the appropriate space to introduce the hospital to tourists (c9)" and "providing extensive advertising to introduce the hospital to tourists (c10)." In addition, this country was able to satisfy tourists in terms of "friendly behavior of medical staff towards tourists (c18)," "having a specific website for hospital introduction (c19)," and "specialized staff (c4)."

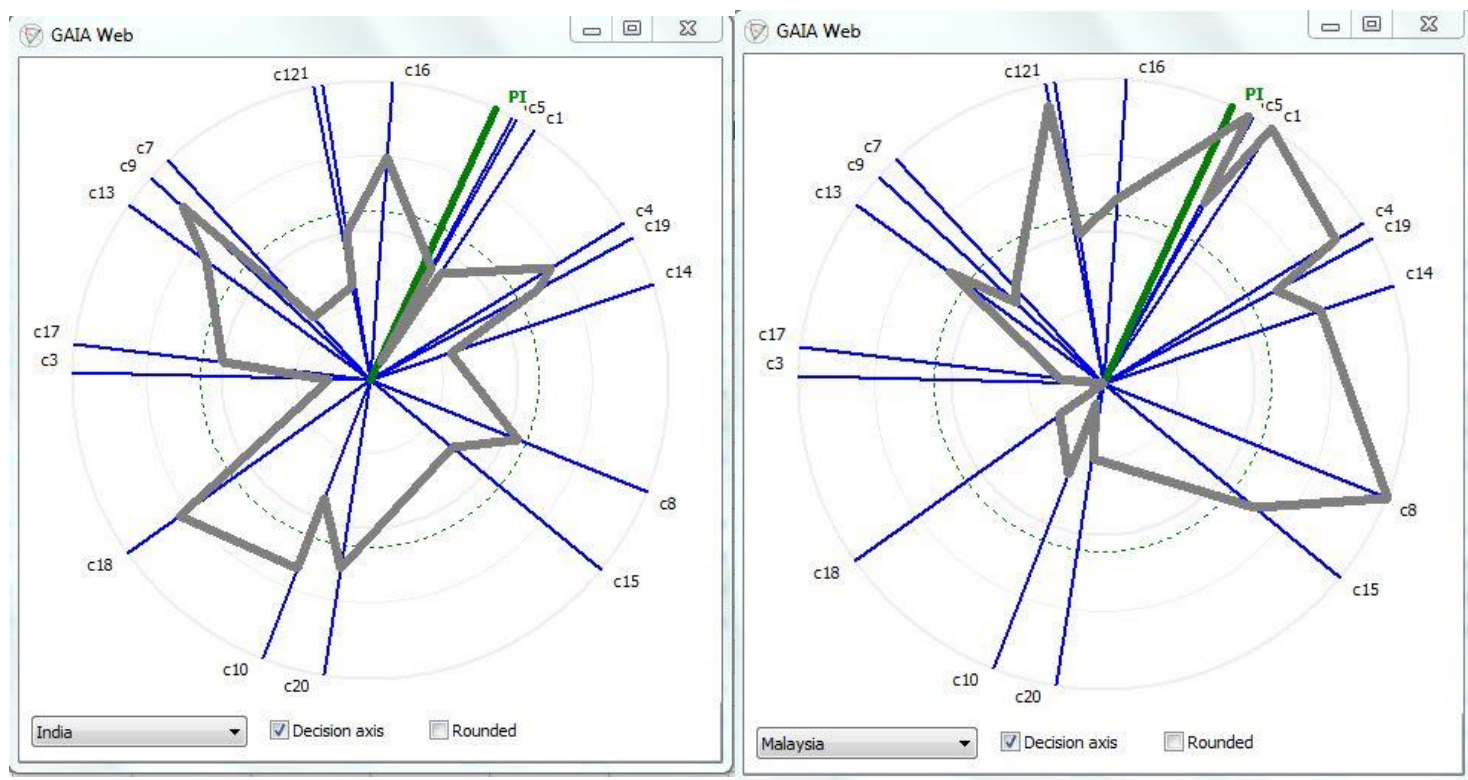

Figure 3. GAIA web. Source: Author's own contribution. 
The right-side plane shows the quality of the criteria for Malaysia. This country performed well in terms of "staff quantity (c1)," "familiarity of staff with foreign languages (c5)," "using modern medical equipment and procedures (c8)," and "spending on marketing and attracting tourists (c12)." This country was weak in terms of "providing extensive advertising to introduce the hospital to tourists (c10)" and "friendly behavior of medical staff towards tourists (c18)".

Figure 4 shows the walking weights chart. This figure is the output of the Visual PROMETHEE software. This figure shows the sensitivity analysis of medical tourism destinations in terms of the criteria considered. The right-side chart shows the sensitivity analysis based on the "staff quantity (c1)." As can be seen by the increase in the weight of this criterion up to $50 \%$ and keeping the weights of the other criteria constant, Malaysia was selected as the top medical tourism destination, followed by Mexico in second rank. It indicates that the two countries were in a good condition in terms of staff quantity. Costa Rica, Taiwan, India, Singapore, Panama, and Brazil ranked third to eighth, respectively. According to this chart, Brazil was weaker than other countries in terms of staff quantity and needs to improve.

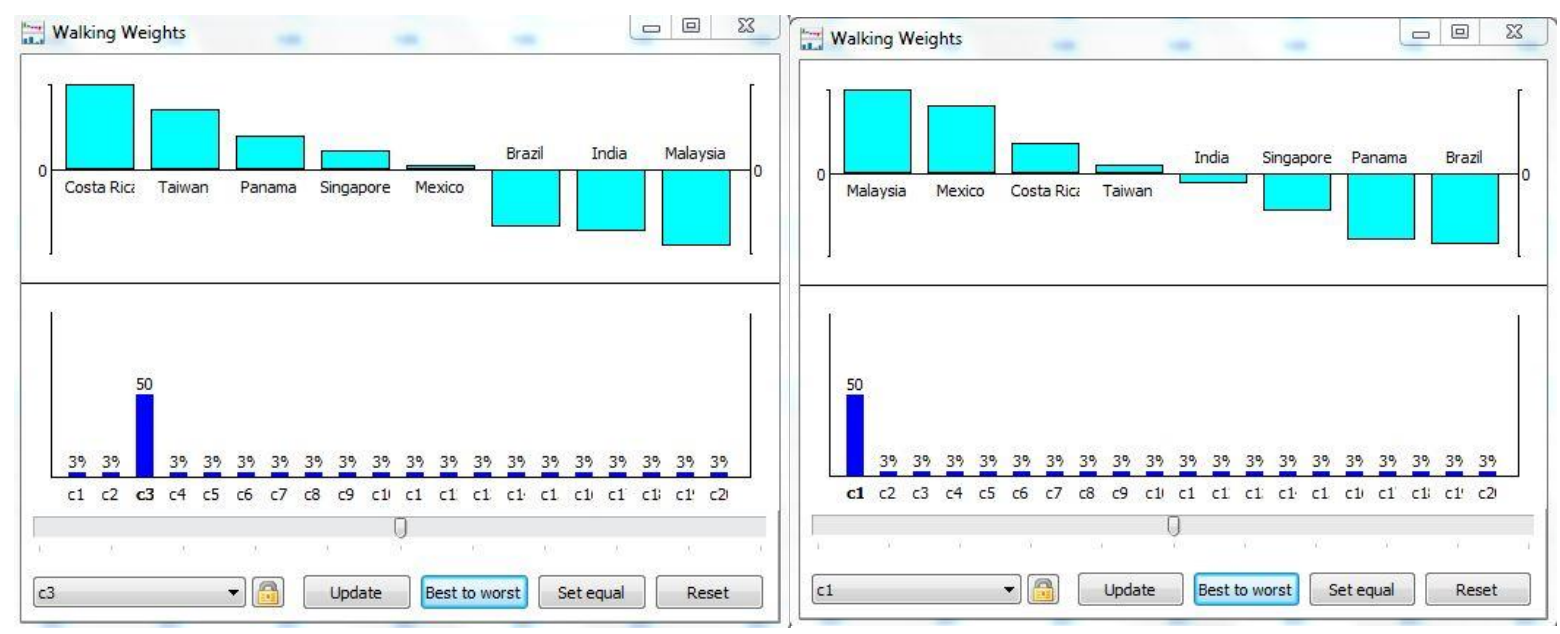

Figure 4. Walking weights. Source: Author's own contribution.

The left-side chart shows the sensitivity analysis of medical tourism destinations based on the "up-to-date staff (c3)." With a 50\% increase in the weight of this criterion, Costa Rica was chosen as the best country. It indicates that this country performed very well in this regard. Taiwan, Panama, Singapore, and Mexico were also ranked second to fifth. Countries that performed poorly in this regard include Brazil, India, and Malaysia, which ranked fifth to eighth. These countries need to make efforts to improve this criterion.

The following Figure 5 shows the PROMETHEE rainbow chart. The criteria with positive net Phi values are at the top of the chart and the criteria with negative net Phi are displayed at the bottom of the chart. India had the best performance compared to other countries in terms of criteria c9, c13, c18, c16, while it did not perform well in terms of criteria c14, c12, c15 and c5. Malaysia had the best performance in terms of criterion c8 and the worst performance in terms of criterion c17. In Panama, c13 was the best and c19 was the worst criterion. 


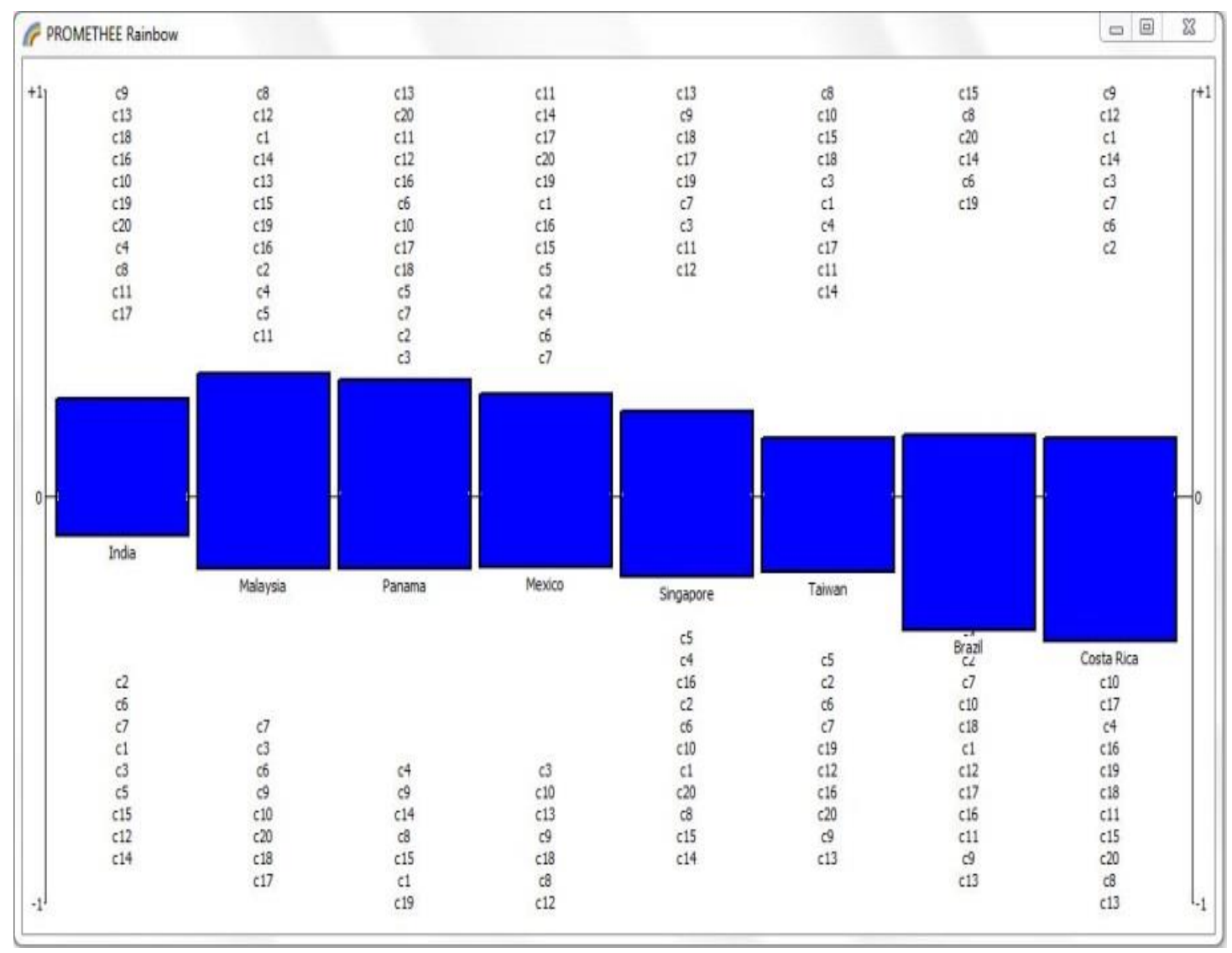

Figure 5. PROMETHEE rainbow. Source: Author's own contribution

Mexico and Singapore had the best performance in terms of criteria c11 and c13, and the worst performance in terms of criteria c12 and c14, respectively. Taiwan had the best performance in terms of criterion $\mathrm{c} 8$ and the worst performance in terms of criterion c13. Brazil performed well only in terms of criteria c15, c8, c20, c14, c6, and c19. In the end, Costa Rica had the best performance in terms of criterion $\mathrm{c} 9$ and the worst performance in terms of criterion c13.

In 2019, 13,232 trips were made from Iran with the intention of medical tourism. Among the trips made were 4398 trips to India. There were also 3425 trips to Malaysia and 2178 trips to Panama. The shares of Mexico, Singapore, and Taiwan for medical tourism were 1011, 938, and 755 trips, respectively. There were also 417 trips to Brazil and 110 trips to Costa Rica $[97,98]$. According to the statistics and their comparison with the results of this study, the accuracy of ranking tourism destinations from the perspective of the Iranian people was confirmed. The results of the real statistics also showed that India was selected as the most popular tourist destination by Iranians.

In order to verify the model, the proposed model was compared with the fuzzy AHP and fuzzy VIKOR approaches.

Table 10 shows the results of comparing the ranking of medical tourism destinations with different approaches. Comparing the results of the proposed approach with the fuzzy AHP approach shows the difference between the 5th and 6th (Taiwan and Singapore) ranks. Comparing the results of the proposed approach with the fuzzy VIKOR approach shows the difference between the 3rd and 4th (Mexico and Panama) ranks. It should be noted that the weights of the criteria in VIKOR were obtained from fuzzy SWARA. Due to the closeness of the ranking of the fuzzy AHP and fuzzy VIKOR approaches with the proposed approach, the accuracy of the proposed model was proved (Appendix A and ??). 
Table 10. Verification of the results.

\begin{tabular}{|c|c|c|c|}
\hline Rank & Proposed Approach & $\begin{array}{c}\text { FUZZY } \\
\text { AHP }\end{array}$ & $\begin{array}{l}\text { FUZZY } \\
\text { VIKOR }\end{array}$ \\
\hline Rank 1 & India & India & India \\
\hline Rank 2 & Malaysia & Malaysia & Malaysia \\
\hline Rank 3 & Panama & Panama & Mexico \\
\hline Rank 4 & Mexico & Mexico & Panama \\
\hline Rank 5 & Singapore & Taiwan & Taiwan \\
\hline Rank 6 & Taiwan & Singapore & Singapore \\
\hline Rank 7 & Brazil & Brazil & Brazil \\
\hline Rank 8 & Costa Rica & Costa Rica & Costa Rica \\
\hline
\end{tabular}

Source: Author's own contribution.

Figure 6 also shows the weight comparisons of the criteria in the fuzzy SWARA and fuzzy AHP methods:

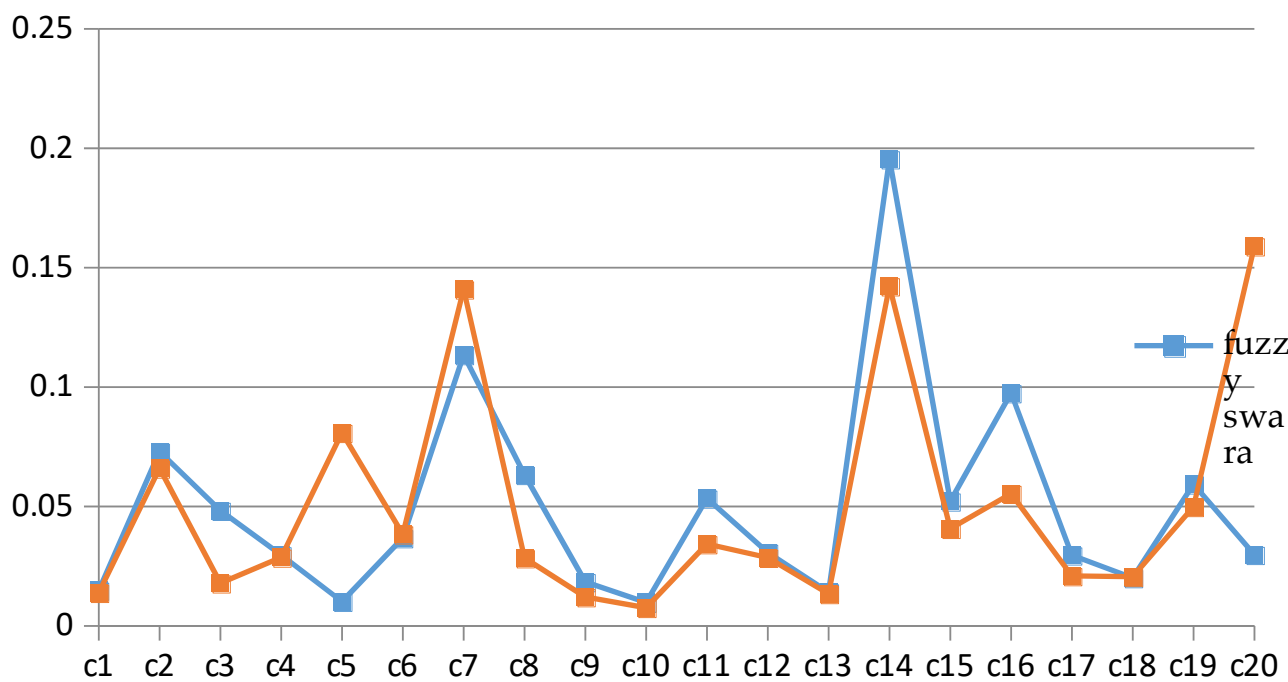

Figure 6. Comparison of criteria weights in fuzzy AHP and fuzzy SWARA. Source: Author's own contribution.

For comparing the results with the previous one obtained in the literature, Levary et al. [57] was selected. The results of Levary et al. [57] also proved the results of our research. Levary et al. [57] also selected India as the first destination. Therefore, comparing the results of other researches in the literature review also proved the results of this research.

Figure 7 shows the results of the criteria sensitivity analysis. For this purpose, the values of the criteria weights were changed and changes in the alternative were observed. The horizontal axis shows the criteria and the vertical axis shows the percentage of changes in the criteria weights. The blue lines indicate the upper limit and the red lines the lower limit. As can be seen from the figure, for example, the upper limit of the first criterion change for that alternative ranking remains constant at $16 \%$ and the lower limit is $10 \%$. 


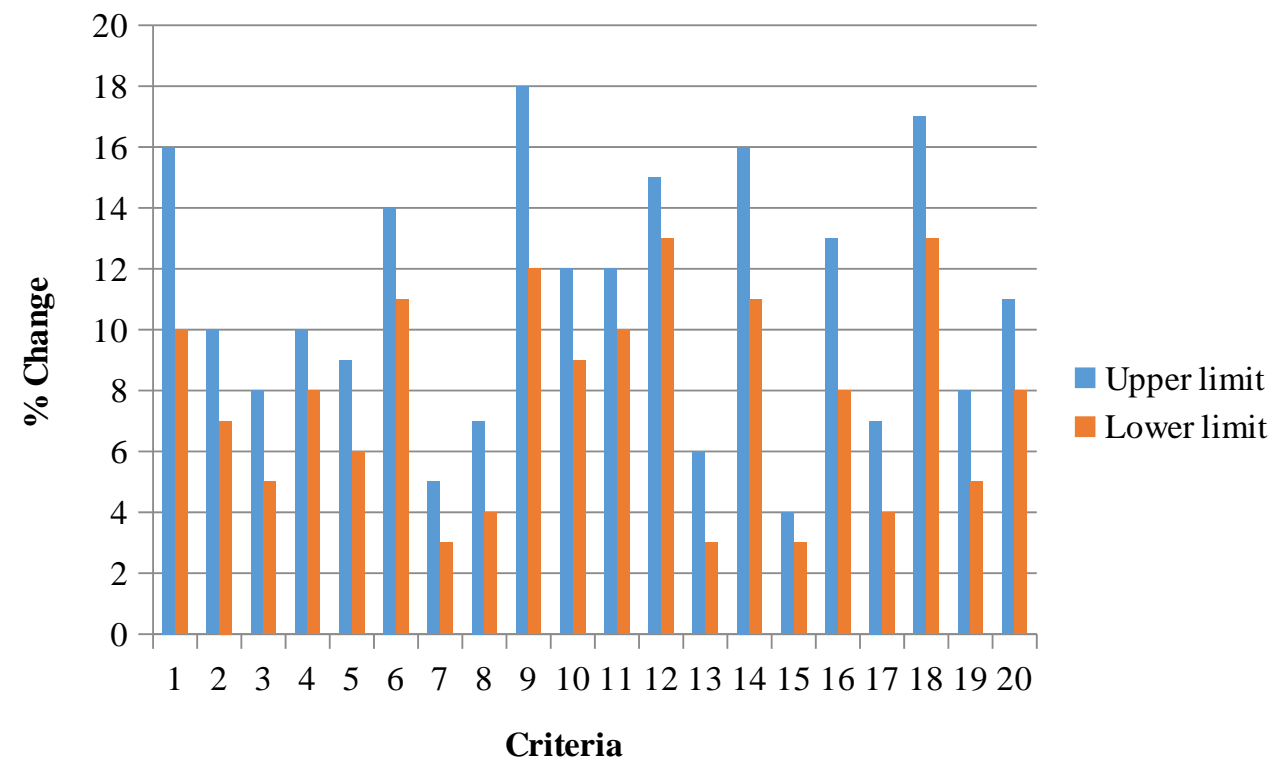

Figure 7. The sensitivity of changes in the criteria. Source: Author's own contribution.

\section{Conclusions}

Health tourism represents one of the fastest growing segments in the tourism industry. Tourism as well as medical tourism can be sustainable if developed and managed, considering both tourists and communities. This can be achieved through community engagement, congestion management, reduction of seasonality, careful planning that respects the limits of capacity and the specificities of each destination, and product diversification.

In this study, using a combined fuzzy SWARA-PROMETHEE approach, famous countries in terms of medical tourism were ranked from the viewpoint of the Iranian people. Therefore, five main criteria, including abilities of skilled staff, applied medical equipment, marketing capability, type of services provided, and application of information and communications technology along with 20 sub-criteria, were extracted. The weights of the criteria were determined using the fuzzy SWARA approach. After determining the weights of the criteria, the medical tourism destinations were ranked using the PROMETHEE approach. Identifying criteria related to sustainability in the subject of medical tourism destinations and prioritizing medical tourism destinations using these criteria are the contributions of this paper. The results showed that India $(\mathrm{Phi}=0.1396)$, Malaysia $(\mathrm{Phi}=0.1128)$, Panama $(\mathrm{Phi}=0.0976)$, Mexico $(\mathrm{Phi}=0.0790)$, Singapore $(\mathrm{Phi}=0.0096)$, Taiwan $(\mathrm{Phi}=-0.0442)$, Brazil (Phi $=-0.1747)$, and Costa Rica $(\mathrm{Phi}=-0.2196)$ were the medical tourism priorities for Iranians, respectively. The weights of criteria for "Abilities of skilled staff," "applied medical equipment," "marketing capability," "type of service provided," and "application of information and communications technology" were $0.176,0.232,0.108,0.395$, and 0.089, respectively. The results of the sensitivity analysis showed that Malaysia and Mexico were in good condition in terms of staff quantity. Also, Brazil performed poorly in terms of quantity staff compared to other countries and needs to improve. In terms of up-to-date staff, Costa Rica had the best performance and Malaysia had the worst performance. Sustainability is a concept that has gained increasing popularity among consumers around the world [99], and its implications for medical tourism are growing. To examine the verification of the proposed approach, the results were compared with the fuzzy AHP and fuzzy VIKOR approaches. Comparing the results of the proposed approach with fuzzy VIKOR approach showed the difference between the 3th and 4th (Mexico and Panama) ranks. Also comparing the results of the proposed approach with fuzzy AHP approach showed the difference between the 5th and 6th (Taiwan and Singapore) ranks. Due to the closeness of the ranking of the fuzzy AHP and fuzzy VIKOR approaches with the proposed approach, the accuracy of the proposed model was proved. 
Some empirical studies [100] revealed that the level of customer satisfaction is directly correlated with their loyalty to the hospital, which is a prerequisite for the progress of the health tourism market. According to certain researchers [101], interest in the preservation of health and quality of life, which includes rest and recuperation, represents the major tourist motivation. According to [102] the category of consumers in the health care system includes the following two main subcategories: external customers, which includes patients, family members of patients, and potential customers, and internal customers, which includes employees and their employers. For instance, Malaysia is perceived as a hub of medical tourism in Southeast Asia, while the health care travel industry is a privatesector-driven [103]. The 1970s established certain Asian countries-Thailand, India and Singapore-as the most popular medical tourism destinations [104].

According to Spulbar et al. (2019), a sustainable development-based approach has significant implications for low and middle-income countries (emerging), considering their main characteristic features such as: demographic dynamics, high degree of poverty, poor quality education, migration, environmental degradation, social inequality, high levels of urbanization, health system deficiencies, rapid technological change, and unsustainable economic growth [105]. Mehdiabadi et al. (2020) argued that considering current challenges, the global economy is very dynamic and constantly changing, so innovation and technological development represent essential aspects in regards to a sustainable perspective [106].

The results of this study can help countries to strengthen their weaknesses. Also, identifying sustainable criteria for medical tourism destinations and prioritizing destinations can help patients to choose destinations tailored to their needs. Sustainable criteria cover all economic, social, and environmental dimensions. Therefore, identifying and prioritizing criteria can help tourism destinations, for example, European or American countries, to strengthen strengths and reduce their negative criteria. This study, like other studies, has some limitations. One of the limitations of this research paper is the lack of access to more extensive statistical databases. Also, due to the qualitative nature of most of the criteria, including them in the questionnaire and converting them into quantitative criteria was another limitation of this research. Other limitations include the use of fuzzy data and their conversion to Crisp data. Finally, this study is limited to Iranians' views on medical tourism destinations. Despite the fact that it is a topic of interest, existing literature does not contain many research studies on the linkage between health care aspects and tourism, especially in the current context of the Covid-19 pandemic.

The following are recommended for future studies:

1. Prioritizing medical tourism destinations based on the viewpoints of the people living in other countries, such as India, China, etc.;

2. Investigating the effect of different countries' policies on their medical tourism, for example, the policies adopted by countries regarding the COVID-19 outbreak;

3. Considering other criteria in addition to sustainability, such as resiliency, etc.;

4. Considering other uncertainty approaches, such as fuzzy type 2, stochastic, and scenario;

5. Predicting the demand for medical tourism in countries using sustainable criteria;

6. Prioritization of medical tourism destinations with regard to the occurrence of crises such as the COVID-19 outbreak.

Author Contributions: All authors contributed equally to this research work. All authors discussed the results and contributed to the final manuscript. All authors have read and agreed to the published version of the manuscript.

Funding: This research received no external funding.

Institutional Review Board Statement: Not applicable.

Informed Consent Statement: Not applicable.

Conflicts of Interest: The authors declare no conflict of interest. 


\section{Appendix A}

FUZZY AHP: In This Article, the Kutlu Gündoğdu and Kahraman (2019) Framework Was Used to Introduce and Apply the Fuzzy AHP Method [107] According to the Following Table Captions:

\begin{tabular}{|c|c|c|c|c|c|c|c|c|c|c|}
\hline & \multicolumn{9}{|c|}{ Initial Comparison Matrices } & \\
\hline & \multicolumn{4}{|c|}{ Left Criteria Is Greater } & \multicolumn{5}{|c|}{ Right Criteria Is Greater } & \\
\hline & AMI & VHI & HI & SMI & EI & SLI & $\mathbf{L I}$ & VLI & ALI & \\
\hline $\mathbf{A}$ & & & & & 1 & & & & & B \\
\hline $\mathbf{A}$ & & & & 1 & & & & & & C \\
\hline $\mathbf{A}$ & & & 1 & & & & & & & D \\
\hline $\mathbf{A}$ & & 1 & & & & & & & & $\mathbf{E}$ \\
\hline $\mathbf{A}$ & & 1 & & & & & & & & $\mathbf{F}$ \\
\hline $\mathbf{A}$ & & 1 & & & & & & & & $\mathbf{G}$ \\
\hline $\mathbf{A}$ & & 1 & & & & & & & & H \\
\hline B & & & & 1 & & & & & & C \\
\hline B & & & & 1 & & & & & & D \\
\hline B & & & 1 & & & & & & & $\mathbf{E}$ \\
\hline B & & 1 & & & & & & & & $\mathbf{F}$ \\
\hline B & & 1 & & & & & & & & G \\
\hline B & & 1 & & & & & & & & H \\
\hline C & & & & 1 & & & & & & D \\
\hline C & & & 1 & & & & & & & $\mathbf{E}$ \\
\hline C & & 1 & & & & & & & & $\mathbf{F}$ \\
\hline C & & 1 & & & & & & & & G \\
\hline C & & 1 & & & & & & & & $\mathbf{H}$ \\
\hline D & & & & 1 & & & & & & $\mathbf{E}$ \\
\hline D & & & 1 & & & & & & & $\mathbf{F}$ \\
\hline D & & & 1 & & & & & & & G \\
\hline D & & 1 & & & & & & & & $\mathbf{H}$ \\
\hline $\mathbf{E}$ & & 1 & & & & & & & & $\mathbf{F}$ \\
\hline $\mathbf{E}$ & & 1 & & & & & & & & G \\
\hline $\mathbf{E}$ & & 1 & & & & & & & & $\mathbf{H}$ \\
\hline $\mathbf{F}$ & & 1 & & & & & & & & $\mathbf{G}$ \\
\hline $\mathbf{F}$ & & 1 & & & & & & & & H \\
\hline G & & 1 & & & & & & & & H \\
\hline
\end{tabular}

Figure A1. Initial Comparison Matrices. Source: Author's own contribution. 


\begin{tabular}{|c|c|c|c|c|c|c|c|c|c|c|c|c|c|c|c|c|c|c|c|c|c|c|c|c|}
\hline \multirow[b]{2}{*}{ A } & \multicolumn{3}{|c|}{ A } & \multicolumn{3}{|c|}{ B } & \multicolumn{3}{|c|}{ C } & \multicolumn{3}{|c|}{ D } & \multicolumn{3}{|c|}{ E } & \multicolumn{3}{|c|}{ F } & \multicolumn{3}{|c|}{ G } & \multicolumn{3}{|c|}{ H } \\
\hline & 0.500 & 0.400 & 0.400 & 0.500 & 0.400 & 0.400 & 0.600 & 0.400 & 0.300 & 0.700 & 0.300 & 0.200 & 0.800 & 0.200 & 0.100 & 0.800 & 0.200 & 0.100 & 0.800 & 0.200 & 0.100 & 0.800 & 0.200 & 0.100 \\
\hline B & 0.400 & 0.500 & 0.400 & 0.500 & 0.400 & 0.400 & 0.600 & 0.400 & 0.300 & 0.600 & 0.400 & 0.300 & 0.700 & 0.300 & 0.200 & 0.800 & 0.200 & 0.100 & 0.800 & 0.200 & 0.100 & 0.800 & 0.200 & 0.100 \\
\hline C & 0.400 & 0.600 & 0.300 & 0.400 & 0.600 & 0.300 & 0.500 & 0.400 & 0.400 & 0.600 & 0.400 & 0.300 & 0.700 & 0.300 & 0.200 & 0.800 & 0.200 & 0.100 & 0.800 & 0.200 & 0.100 & 0.800 & 0.200 & 0.100 \\
\hline D & 0.300 & 0.700 & 0.200 & 0.400 & 0.600 & 0.300 & 0.400 & 0.600 & 0.300 & 0.500 & 0.400 & 0.400 & 0.600 & 0.400 & 0.300 & 0.700 & 0.300 & 0.200 & 0.700 & 0.300 & 0.200 & 0.800 & 0.200 & 0.100 \\
\hline $\mathbf{E}$ & 0.200 & 0.800 & 0.100 & 0.300 & 0.700 & 0.200 & 0.300 & 0.700 & 0.200 & 0.400 & 0.600 & 0.300 & 0.500 & 0.400 & 0.400 & 0.800 & 0.200 & 0.100 & 0.800 & 0.200 & 0.100 & 0.800 & 0.200 & 0.100 \\
\hline F & 0.200 & 0.800 & 0.100 & 0.200 & 0.800 & 0.100 & 0.200 & 0.800 & 0.100 & 0.300 & 0.700 & 0.200 & 0.200 & 0.800 & 0.100 & 0.500 & 0.400 & 0.400 & 0.800 & 0.200 & 0.100 & 0.800 & 0.200 & 0.100 \\
\hline G & 0.200 & 0.800 & 0.100 & 0.200 & 0.800 & 0.100 & 0.200 & 0.800 & 0.100 & 0.300 & 0.700 & 0.200 & 0.200 & 0.800 & 0.100 & 0.200 & 0.800 & 0.100 & 0.500 & 0.400 & 0.400 & 0.800 & 0.200 & 0.100 \\
\hline H & 0.200 & 0.800 & 0.100 & 0.200 & 0.800 & 0.100 & 0.200 & 0.800 & 0.100 & 0.200 & 0.800 & 0.100 & 0.200 & 0.800 & 0.100 & 0.200 & 0.800 & 0.100 & 0.200 & 0.800 & 0.100 & 0.500 & 0.400 & 0.400 \\
\hline
\end{tabular}

\begin{tabular}{|c|c|c|c|c|}
\hline \multicolumn{3}{|c|}{ Spherical Fuzzy Weights } & \multirow{2}{*}{$\begin{array}{c}\begin{array}{c}\text { Crisp } \\
\text { Weights }\end{array} \\
0.162\end{array}$} & \multirow{2}{*}{$\begin{array}{c}\text { Crisp Weights } \\
0.162\end{array}$} \\
\hline 0.717 & 0.273 & 0.218 & & \\
\hline 0.686 & 0.306 & 0.240 & 0.153 & 0.153 \\
\hline 0.673 & 0.329 & 0.226 & 0.151 & 0.151 \\
\hline 0.598 & 0.405 & 0.255 & 0.132 & 0.132 \\
\hline 0.612 & 0.407 & 0.202 & 0.138 & 0.138 \\
\hline 0.526 & 0.510 & 0.184 & 0.118 & 0.118 \\
\hline 0.427 & 0.607 & 0.191 & 0.093 & 0.093 \\
\hline 0.263 & 0.734 & 0.189 & 0.053 & 0.053 \\
\hline
\end{tabular}

\section{\begin{tabular}{|l|l|l|} 
Consistency Ratio (CR) & 0.2333 & Compare with 0.1; It should be less than 0.1
\end{tabular}}

Figure A2. Integrated Spherical Fuzzy Comparison Matrix. Source: Author's own contribution.

Appendix B

FUZZY VIKOR: In this article, the Chang (2014) framework was used to introduce and apply the fuzzy VIKOR method [108] according to the following table captions: 


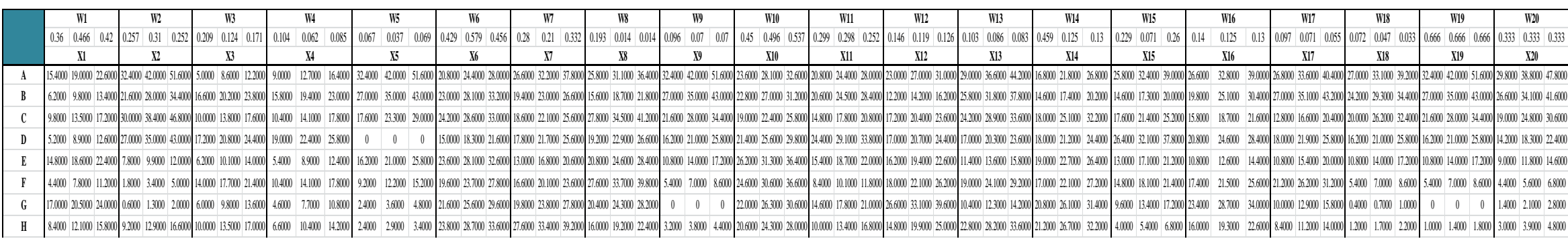

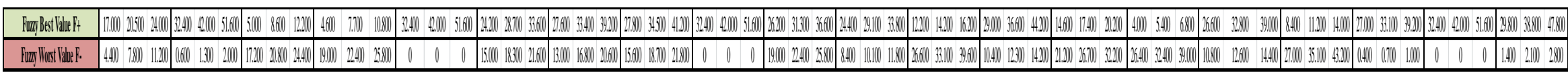

Figure A3. Integrated Matrix Source: Author's own contribution.

\begin{tabular}{|c|c|c|c|c|c|c|c|c|c|c|c|c|c|c|c|c|c|c|c|c|c|c|c|c|c|c|c|c|c|c|c|c|c|c|}
\hline & $\begin{array}{c}\mathrm{T1} \\
0.366 .466 .4 \\
\mathrm{X1}\end{array}$ & \multicolumn{2}{|c|}{\begin{tabular}{|c|c|}
112 \\
0.57 \\
0.31 & 0.252 \\
$X 2$ \\
\end{tabular}} & \multicolumn{2}{|c|}{\begin{tabular}{|c|}
13 \\
0.219 \\
0.1240 .171 \\
$X 3$ \\
\end{tabular}} & \multicolumn{3}{|c|}{ W4 } & \multicolumn{3}{|c|}{115} & \begin{tabular}{|c|}
116 \\
0.4920590 .56
\end{tabular} & \multicolumn{2}{|c|}{177} & & & & & 112 & & & & & & & 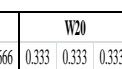 \\
\hline & & 380.1375 & & & 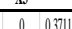 & 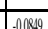 & $\frac{A 4}{0258}$ & & -03271 & $e^{2}$ & 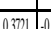 & $\frac{A v}{203}$ & $\sqrt{10.202020}$ & & 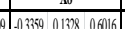 & 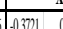 & & & & 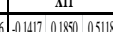 & 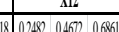 & & 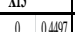 & 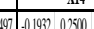 & & $\frac{A 19}{120}$ & & & & All & & & $\frac{19}{4 y}$ & $\frac{X 201}{2007}$ \\
\hline & 0.5590 .098 & 0.020 .0 .0920 & 02750.5852 & & 0.5990 .09691 & 0.258 & 0.519 & & & 0.1579 & 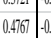 & 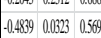 & 190.0820 & 0.3969 & 0.2340 .672 & 0.25640 .1 .1 & & & & & 0 & & 0.1420 & $=0.2000$ & 0.3182 & 90.340 .457$. & -1.12838 & 0230 & & & 70.09979 & & & \\
\hline & 20.35710 & & & & & 0.0189 & 0.3019 & 0.026 & 0.659 & 0.3240 & $0.6599-0.2 x-3$ & 0.47310 .0055 & 64 0 & & & & & & & & & & & 0.475 & & & 0.773 & 15000 & & & & & & \\
\hline & & 520.020207 & 0.1330 .4284 & & 0.6289 & 0.3688 & 0.0944 & & 0 & 0 & & 0.19380 .5951 & 0.06330 & 0.4660 .86168 & 880.04690 .45310 .0 .534 & 40.1290 .040 & & 0.020150. & 0.32920 .8363 & $6-0.3010$ & & 0.158 & & (7).0.1250 0.21 & 0.568 & 0.5000 .0769 & 5]- 0.0668 & 0298 & & & & & & \\
\hline & 350.0960 .0469 & 604040000 a.t. & 0.6240 .5838 & & 0.07370 .699 & .12577 & 0.056 & 0.639 & 0.129 & & $0.6600-0.0$ & 0.0456160 .0230 .537 & 760.2620. & & 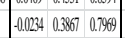 & & 0.5960 .9097 & & & & & & & & & & 140.426 & 0.7163 & & & & & & \\
\hline & 0.2590 .0 .590 & & 0.3690 .5 & & & 0.0189 & 0.3019 & 0.026 & 0.333 & 0.5750 & 0.817 .0 .0 & 0.19950 & & & & 460.20 .67 & & & & & & & & & & 0.2860 .328 & 0.035 & 0.4007 & & & & & 20.6833 & 0.4570 .71550 \\
\hline & $\begin{array}{lll}-0.3571 & 0 & 0.357\end{array}$ & 35110.5610.7 & 0.990 & -0.31960 .0 .6 & 0.6690 .433 & .0295 & 0 & 0.295 & 0.5399 & 0.742 & 0.9355 .0 .2 & .029030 .16670 .065 & 52.000760. & 0.36640 .7465 & $15-0.01560 .39840 .8125$ & $5[0$ & 0 & -125000 & 0.2840 .8255 & 50.1390 .0 .490 .0359 & & 0.479 & & 0.09410 .493 & 0.555 & 0.00000 .02860 & 17]-02204 & 0.144 & & . & 01260.65010 .851 & & & 108900.0999 \\
\hline & & & & & & & & & & & & & & & & & & & & & & & & & & & & & & & & & & \\
\hline
\end{tabular}

\section{5}

\begin{tabular}{|c|c|c|c|c|c|c|c|c|c|c|c|c|c|c|c|}
\hline \multirow{2}{*}{$\frac{\text { Alternatives }}{\mathbf{A}}$} & \multicolumn{3}{|c|}{$\mathbf{S i}$} & \multicolumn{3}{|c|}{$\mathbf{R i}$} & \multicolumn{3}{|c|}{ Qi } & \multicolumn{2}{|c|}{ Crisp $S_{i}$} & \multicolumn{2}{|c|}{ Crisp Ri } & \multicolumn{2}{|c|}{ Crisp Qi } \\
\hline & $\mid-1.2141$ & 0.5283 & 2.4182 & 0.1243 & 0.1339 & 0.3966 & -0.6047 & $\mathrm{O}$ & 0.6543 & 0.5774 & $\mathbf{1}$ & 0.2183 & $\mathbf{1}$ & 0.0165 & 1 \\
\hline $\mathbf{B}$ & -0.5931 & 0.9961 & 2.7619 & 0.0661 & 0.2544 & 0.4211 & -0.5905 & 0.1507 & 0.7103 & 1.0550 & 2 & 0.2472 & 2 & 0.0902 & 2 \\
\hline $\mathbf{C}$ & -0.3467 & 1.2465 & 3.0107 & 0.0707 & 0.2508 & 0.5370 & -0.5614 & 0.1733 & 0.8346 & 1.3035 & 3 & 0.2862 & 3 & 0.1488 & 3 \\
\hline $\mathbf{D}$ & 0.2558 & 1.6942 & 3.4000 & 0.1282 & 0.3237 & 0.4638 & -0.4505 & 0.2814 & 0.8122 & 1.7833 & 6 & 0.3053 & 5 & 0.2143 & 5 \\
\hline $\mathbf{E}$ & 0.0179 & 1.4045 & 3.0359 & 0.1962 & 0.3614 & 0.5266 & -0.4170 & 0.2837 & 0.8283 & 1.4861 & 5 & 0.3614 & 6 & 0.2317 & 6 \\
\hline $\mathbf{F}$ & 0.5896 & 2.1152 & 3.6588 & 0.3072 & 0.4517 & 0.5963 & -0.2638 & 0.4336 & 0.9516 & 2.1212 & 8 & 0.4517 & 7 & 0.3738 & 7 \\
\hline G & 0.0897 & 1.2813 & 2.6366 & 0.1938 & 0.2634 & 0.4455 & -0.4117 & 0.1876 & 0.7182 & 1.3359 & 4 & 0.3009 & 4 & 0.1647 & 4 \\
\hline $\mathbf{H}$ & 0.5014 & 1.8701 & 3.3289 & 0.3950 & 0.5240 & 0.6531 & -0.1981 & 0.4700 & 0.9661 & 1.9001 & 7 & 0.5240 & 8 & 0.4127 & 8 \\
\hline
\end{tabular}

Figure A4. Fuzzy Difference Dij. Source: Author's own contribution. 


\section{References}

1. Choi, S.H. Measurement of Sustainable Development Progress for Managing Community Tourism. Ph.D. Thesis, Texas A\&M University, College Station, TX, USA, 2003.

2. Jurowski, C.; Uysal, M.; Williams, D.R. A Theoretical Analysis of Host Community Resident Reactions to Tourism. J. Travel Res. 1997, 36, 3-11. [CrossRef]

3. Perkumienė, D.; Vienažindienè, M.; Švagždienè, B. Cooperation Perspectives in Sustainable Medical Tourism: The Case of Lithuania. Sustainability 2019, 11, 3584. [CrossRef]

4. Al-Talabani, H.; Kilic, H.; Ozturen, A.; Qasim, S.O. Advancing Medical Tourism in the United Arab Emirates: Toward a Sustainable Health Care System. Sustainability 2019, 11, 230. [CrossRef]

5. Pololikashvili, Z. Overtourism? Understanding and Managing Urban Tourism Growth beyond Perceptions. Executive Summary. 2018. Available online: https://www.e-unwto.org/doi/book/10.18111/9789284420070 (accessed on 7 February 2019).

6. Heung, V.C.S.; Kucukusta, D.; Song, H. A Conceptual Model of Medical Tourism: Implications for Future Research. J. Travel Tour. Mark. 2010, 27, 236-251. [CrossRef]

7. Connell, J. Contemporary medical tourism: Conceptualization, culture and commodification. Tour. Manag. 2013, 34, 1-13. [CrossRef]

8. Zarei, A.; Feiz, D.; Minbashrazgah, M.M.; Maleki, F. Factors influencing selection of medical tourism destinations: A special niche market. Int. J. Health Manag. 2018, 1-7. [CrossRef]

9. Moreira, P. Health and medical tourism: Health management and marketing research challenges. Int. J. Healthc. Manag. 2014, 7 , 221-222. [CrossRef]

10. Smith, R.D. Foreign direct investment and trade in health services: A review of the literature. Soc. Sci. Med. 2004, 59, 2313-2323. [CrossRef]

11. Smith, P.C.; Forgione, D.A. Global Outsourcing of Healthcare: A Medical Tourism Decision Model. J. Inf. Technol. Case Appl. Res. 2007, 9, 19-30. [CrossRef]

12. Beth, K. Traveling for medical care in a global world. Med. Anthropol. 2010, 29, 344-362.

13. Hadian, M.; Jabbari, A.; Mousavi, S.H.; Sheikhbardsiri, H. Medical tourism development: A systematic review of economic aspects. Int. J. Health Manag. 2019, 1-7. [CrossRef]

14. Radovcic, Z.; Nola, I.A. Medical tourism globe-trotting: Features, impacts, and risks. Int. J. Health Manag. 2018, 1-7. [CrossRef]

15. Sandberg, D.S. Medical tourism: An emerging global healthcare industry. Int. J. Health Manag. 2017, 10, 281-288. [CrossRef]

16. Aiwerioghene, E.M.; Singh, M.; Ajmera, P. Modelling the factors affecting Nigerian medical tourism sector using an interpretive structural modelling approach. Int. J. Health Manag. 2019, 1-13. [CrossRef]

17. Gaines, J.; Lee, C.V. Medical Tourism. In Travel Medicine; Elsevier BV: Oxford, UK, 2019; pp. 371-375.

18. Moghadam, F.N.; Asl, I.M.; Hessam, S.; Farahani, M.M. In search a medical tourism marketing pattern in Iran: The case of cultural sensitivities. Int. J. Health Manag. 2020, 27, 1-6. [CrossRef]

19. Ganguli, S.; Ebrahim, A.H. A qualitative analysis of Singapore's medical tourism competitiveness. Tour. Manag. Perspect. 2017, 21, 74-84. [CrossRef]

20. Shukla, U.N.; Kulshreshtha, S.K. United Arab Emirates as a Global Medical Tourism Destination: An Explorative Study. In Global Developments in Healthcare and Medical Tourism; IGI Global: Hershey, PA, USA, 2020; pp. 277-290.

21. The World Tourism Organization (UNWTO). Available online: https://www.unwto.org/ (accessed on 1 July 2020).

22. UNWTO/ETC, Report on Health Tourism, (2018) Madrid, Spain, The World Tourism Organization (UNWTO), together with the European Travel Commission (ETC), PR No.: PR 18100. Available online: https://www.unwto.org/global/press-release/2018-1 2-20/unwtoetc-launch-report-health-tourism (accessed on 27 December 2018).

23. Dang, H.-S.; Nguyen, T.-M.-T.; Wang, C.-N.; Day, J.-D.; Dang, T.M.H. Dang Grey System Theory in the Study of Medical Tourism Industry and Its Economic Impact. Int. J. Environ. Res. Public Health 2020, 17, 961. [CrossRef]

24. Ko, T.G.; An, M.E. A System Approach to the Framework of Medical Tourism Industry. Korea J. Hosp. Manag. $2020,25,32-45$.

25. Mathijsen, A. Home, sweet home? Understanding diasporic medical tourism behavior. Exploratory research of Polish immigrants in Belgium. Tour. Manag. 2019, 72, 373-385. [CrossRef]

26. Momeni, K.; Janati, A.; Imani, A.; Khodayari-Zarnaq, R. Barriers to the development of medical tourism in East Azerbaijan province, Iran: A qualitative study. Tour. Manag. 2018, 69, 307-316. [CrossRef]

27. Suess, C.; Baloglu, S.; Busser, J. Perceived impacts of medical tourism development on community wellbeing. Tour. Manag. 2018, 69, 232-245. [CrossRef]

28. Kim, S.; Arcodia, C.; Kim, I. Critical Success Factors of Medical Tourism: The Case of South Korea. Int. J. Environ. Res. Public Health 2019, 16, 4964. [CrossRef] [PubMed]

29. Cesario, S.K. Implications of Medical Tourism. Nurs. Women's Health 2018, 22, 269-273. [CrossRef] [PubMed]

30. Skountridaki, L. Barriers to business relations between medical tourism facilitators and medical professionals. Tour. Manag. 2017, 59, 254-266. [CrossRef]

31. Ormond, M. International Medical Travel or Medical Tourism. In International Encyclopedia of Human Geography; Elsevier BV: London, UK, 2020; pp. 373-377. 
32. Beladi, H.; Chao, C.C.; Ee, M.S.; Hollas, D. Medical tourism and health worker migration in developing countries. Econ. Model. 2015, 46, 391-396. [CrossRef]

33. Lunt, N.; Horsfall, D.; Hanefeld, J. Medical tourism: A snapshot of evidence on treatment abroad. Maturiats 2016, 88, 37-44. [CrossRef]

34. Teays, W.; Gordon, J.S.; Renteln, A.D. Global Bioethics and Human Rights: Contemporary Perspectives, 2nd ed.; Rowman \& Littlefield Publishers: London, UK, 2020; p. 366. ISBN 1538123746.

35. Turner, L. First World Health Care at Third World Prices: Globalization, Bioethics and Medical Tourism. BioSocieties 2007, 2, 303-325. [CrossRef]

36. Lunt, N.; Carrera, P. Systematic review of web sites for prospective medical tourists. Tour. Rev. 2011, 66, 57-67. [CrossRef]

37. Lee, T.J.; Han, J.-S.; Ko, T.G. Health-Oriented Tourists and Sustainable Domestic Tourism. Sustainability 2020, 12, 4988. [CrossRef]

38. Khan, M.J.; Khan, F.; Amin, S.; Chelliah, S. Perceived Risks, Travel Constraints, and Destination Perception: A Study on Sub-Saharan African Medical Travellers. Sustainability 2020, 12, 2807. [CrossRef]

39. Gan, L.L.; Frederick, J.R. Medical tourism facilitators: Patterns of service differentiation. J. Vacat. Mark. 2011, 17, 165-183. [CrossRef]

40. Hall, C.M. Health and medical tourism: A kill or cure for global public health? Tour. Rev. 2011, 66, 4-15. [CrossRef]

41. Lee, C.-W.; Li, C. The Process of Constructing a Health Tourism Destination Index. Int. J. Environ. Res. Public Health $2019,16,4579$. [CrossRef] [PubMed]

42. Wu, Z.; Guo, Q. Research on the development strategy of health tourism industry. Chin. J. Health Policy 2014, 7, 7-11.

43. Spulbar, C.; Birau, R.; Trivedi, J. Global Trends, Practices, and Challenges in Contemporary Tourism and Hospitality Management. In Understanding the Importance of Banking System in Romanian Tourism and Hospitality Industry; IGI Global Publishing: Hershey, PA, USA, 2019; Chapter 7; pp. 135-150. [CrossRef]

44. Çavmak, D.; Çavmak, Ş. Using AHP to Prioritize Barriers in Developing Medical Tourism: Case of Turkey. Int. J. Travel Med. Glob. Health 2020, 8, 73-79. [CrossRef]

45. Farzin, M.; Afsar, A.; Dabir, A.; Zandi, E. Hybrid modeling for forecasting domestic medical tourism demand in Tehran. J. Health Adm. 2019, 21, 51-64. Available online: http://jha.iums.ac.ir/article-1-2791-en.html (accessed on 25 October 2020). [CrossRef]

46. Nilashi, M.; Samad, S.; Manaf, A.A.; Ahmadi, H.; Rashid, T.A.; Munshi, A.; Almukadi, W.; Ibrahim, O.; Ahmed, O.H. Factors influencing medical tourism adoption in Malaysia: A dematel-fuzzy topsis approach. Comput. Ind. Eng. 2019, 137. [CrossRef]

47. Luo, Y.; Lian, Y.; Yu, K.; Sun, L. Using Analytic Hierarchy Process (AHP) for discussing key success factors in the sustainable development of healthy cities. Preprints 2019, 1, 2019050390.

48. Yildı, M.S.; Khan, M.M. Factors Affecting the Choice of Medical Tourism Destination: A Case Study of Medical Tourists from the Arab Region in Turkey. J. Health Manag. 2019, 21, 465-475. [CrossRef]

49. Arif, Y.M.; Nugroho, S.M.S.; Hariadi, M. Selection of Tourism Destinations Priority using 6AsTD Framework and TOPSIS. In Proceedings of the 2019 International Seminar on Research of Information Technology and Intelligent Systems (ISRITI), Yogyakarta, Indonesia, 5-6 December 2019; pp. 346-351.

50. Mayakul, T.; Kiattisin, S.; Prasad, R. A Sustainable Medical Tourism FrameworkBased on the Enterprise ArchitectureDesign: The Case in Thailand. J. Green Eng. 2018, 8, 359-388. [CrossRef]

51. NajafiNasab, M.; Agheli, L.; Viegas Andrade, M.; Sadeghi, H.; FarajiDizaji, S. Determinants of Medical Tourism Expansion in Iran: Structural Equation Modeling Approach. Iran. J. Econ. Stud. 2018, 7, 169-189.

52. Rezaeenour, J.; Mohabbati, M.R.; Masoumikashani, M.H. The Evaluation of Hospital Services Quality in Qom Province with the Approach of Medical Tourism Development by Combination of Fuzzy AHP and TODIM Methods. Tour. Dev. 2018, 7, $20-40$.

53. Karami, F.; Bayati Khatibi, M.; Talebzadeh Shoushtari, A. Determining and prioritizing factors affecting the development of medical tourism with an emphasis on domestic tourists (Case study: City of Mashhad). J. Geogr. Reg. Dev. 2017, 14, 109-128.

54. Morovati Sharifabadi, A.; AsadianArdakani, F. Offering a model with the hybrid method of Fuzzy TOPSIS and structuralinterpretive modeling in Yazd. J. Health Adm. 2014, 17, 73-88.

55. Tsaur, S.-H.; Wang, C.-H. The Evaluation of Sustainable Tourism Development by Analytic Hierarchy Process and Fuzzy Set Theory: An Empirical Study on the Green Island in Taiwan. Asia Pac. J. Tour. Res. 2007, 12, 127-145. [CrossRef]

56. Dreisbach, S.M.; Vij, M.; Dreisbach, J.L. Travel Motivations of Cancer Patients. In Advances in Hospitality, Tourism, and the Services Industry; IGI Global: Hershey, PA, USA, 2020; pp. 78-95.

57. Levary, R.R. Multiple-criteria approach to ranking medical tourism destinations. Thunderbird Int. Bus. Rev. 2011, 53, 529-537. [CrossRef]

58. Pilkington, M. Can Blockchain Technology Help Promote New Tourism Destinations? The Example of Medical Tourism in Moldova. SSRN Electron. J. 2017. [CrossRef]

59. Kobylinski, Z. Cultural Heritage Values and Ownership. In Counterpoint Essays in Archaeology and Heritage Studies; Bergerbrant, S., Sabatini, S., Eds.; Hadrian Books: Oxford, UK, 2013; pp. 719-724.

60. Agbeh, A.; Jurkowski, E. Medical Tourism: An Emerging Terrain Background. J. Tour. Hospit. 2015, 4, 1000186.

61. Ruggeri, K.; Zálišs, L.; Meurice, C.R.; Hilton, I.; Ly, T.-L.; Zupan, Z.; Hinrichs, S. Evidence on global medical travel. Bull. World Health Organ. 2015, 93, 785-789. [CrossRef] 
62. Smith, M.; Health, K. Tourism and Hospitality: Spas, Wellness and Medical Travel. Routledge. 2019. Available online: https://www.routledge.com/Health-Tourism-and-Hospitality-Spas-Wellness-and-Medical-Travel-2nd/Smith-Puczko/p/ book/9780415638647 (accessed on 24 February 2019).

63. Chuang, T.C.; Liu, J.S.; Lu, L.Y.; Lee, Y. The main paths of medical tourism: From transplantation to beautification. Tour. Manag. 2014, 45, 49-58. [CrossRef]

64. Ormond, M.; Sulianti, D. More than medical tourism: Lessons from Indonesia and Malaysia on South-South intra-regional medical travel. Curr. Issues Tour. 2017, 20, 94-110. [CrossRef]

65. Rieger, T. Sustainability and Health Tourism. In Sustainability in Tourism; Springer Science and Business Media LLC, Gabler: Wiesbaden, Germany, 2013; pp. 53-68.

66. Herrera, M.R.G.; Sasidharan, V.; Hernández, J.A.Á.; Herrera, L.D.A. Quality and sustainability of tourism development in Copper Canyon, Mexico: Perceptions of community stakeholders and visitors. Tour. Manag. Perspect. 2018, 27, 91-103. [CrossRef]

67. Beladi, H.; Chao, C.C.; Ee, M.S.; Hollas, D. Does Medical Tourism Promote Economic Growth? A Cross-Country Analysis. J. Travel Res. 2017, 58, 121-135. [CrossRef]

68. Darwazeh, D. Medical Tourism: Establishing a Sustainable Medical Facility. 2011. Available online: https://uwspace.uwaterloo. ca/bitstream/handle/10012/6343/darwazeh_durgham.pdf? (accessed on 6 January 2019).

69. Fetscherin, M.; Stephano, R.-M. The medical tourism index: Scale development and validation. Tour. Manag. 2016, 52, 539-556. [CrossRef]

70. Goffi, G.; Cucculelli, M.; Masiero, L. Fostering tourism destination competitiveness in developing countries: The role of sustainability. J. Clean. Prod. 2019, 209, 101-115. [CrossRef]

71. Croes, R.; Ridderstaat, J.; Van Niekerk, M. Connecting quality of life, tourism specialization, and economic growth in small island destinations: The case of Malta. Tour. Manag. 2018, 65, 212-223. [CrossRef]

72. Voigt, C.; Laing, J.H. Journey into Parenthood: Commodification of Reproduction as a New Tourism Niche Market. J. Travel Tour. Mark. 2010, 27, 252-268. [CrossRef]

73. Sureka, M.; Sahayajenci, K.; Subramani, A.K. Customer Satisfaction and Service Quality towards Naturals Parlour, Chennai. ZENITH Int. J. Multidiscip. Res. 2015, 5, 35-41.

74. Roy, J.; Chatterjee, K.; Bandyopadhyay, A.; Kar, S. Evaluation and selection of medical tourism sites: A rough analytic hierarchy process based multi-attributive border approximation area comparison approach. Expert Syst. 2017, 35, e12232. [CrossRef]

75. Tasci, M.E.; Görener, A. Evaluating the Strategies of Medical Tourism Sector through AHP and Moora in a SWOT Framework. J. Glob. Strat. Manag. 2016, 2, 15. [CrossRef]

76. Bies, W.; Zacharia, L. Medical tourism: Outsourcing surgery. Math. Comput. Model. 2007, 46, 1144-1159. [CrossRef]

77. Rezaee, P. Selection of nomadic tourism sites with GIS and Topsis model (case study: Chaharmahal and Bakhtiari province). J. Stud. Hum. Settl. Plan. 2019, 13, 951-969.

78. Modiri, M.; Karimi Shirazi, H.; Hashemi Dehaghi, Z. Choosing medical tourism strategy based on swot and fuzzy multi-criteria decision making. J. Health Adm. 2017, 20, 23-37.

79. Taghvaei, M.; Goodarzi, M. Development and Prioritization of Medical Tourism Development Strategies (Case Study: Shiraz Metropolis); Islamic Azad University: Marvdashteh, Iran, 2016; Volume 7, pp. 1-22.

80. Chen, C. Using DEMATEL Method for Medical Tourism Development in Taiwan. Am. J. Tour. Res. 2012, 1, 26-32. [CrossRef]

81. Yazdi, M.R.T.; Barazandeh, H. Identifying and Ranking Health Tourism Development Barriers in Iran Using Fuzzy VIKOR Method. Asian Soc. Sci. 2016, 12, 54. [CrossRef]

82. Hung, Y.-H.; Ma, J.; Chou, J.C.-L.; Tzeng, G.-H. Improving medical tourism services based on a hybrid MCDM model combined by DANP and VIKOR techniques. In 2014 IEEE International Conference on Management of Innovation and Technology, Proceedings of the 2014 IEEE International Conference on Management of Innovation and Technology, Singapore, Singapore, 23-25 September 2014; IEEE: New York, NY, USA, 2014; pp. 486-488.

83. Abadi, F.A.; Sahebi, I.G.; Arab, A.; Alavi, A.; Karachi, H. Application of best-worst method in evaluation of medical tourism development strategy. Decis. Sci. Lett. 2018, 7, 77-86. [CrossRef]

84. Zolfani, S.H.; Saparauskas, J. New Application of SWARA Method in Prioritizing Sustainability Assessment Indicators of Energy System. Eng. Econ. 2014, 24, 408-414. [CrossRef]

85. Liu, Z.; Qu, S.; Goh, M.; Huang, R.; Wang, S. Optimization of fuzzy demand distribution supply chain using modified sequence quadratic programming approach. J. Intell. Fuzzy Syst. 2019, 36, 6167-6180. [CrossRef]

86. Ulutaş, A.; Karakuş, C.B.; Topal, A. Location selection for logistics center with fuzzy SWARA and CoCoSo methods. J. Intell. Fuzzy Syst. 2020, 38, 4693-4709. [CrossRef]

87. Keshavarz-Ghorabaee, M.; Amiri, M.; Zavadskas, E.K.; Antuchevičiene, J. A new hybrid fuzzy MCDM approach for evaluation of construction equipment with sustainability considerations. Arch. Civ. Mech. Eng. 2018, 18, 32-49. [CrossRef]

88. Ulutaş, A. University Website Performance Evaluation Using Fuzzy SWARA and WASPAS-F. In Examining Optoelectronics in Machine Vision and Applications in Industry 4.0; IGI Global: Hershey, PA, USA, 2019; pp. 151-165.

89. Keršulienè, V.; Zavadskas, E.K.; Turskis, Z. Selection of rational dispute resolution method by applying new step-wise weight assessment ratio analysis (SWARA). J. Bus. Econ. Manag. 2010, 11, 243-258. [CrossRef]

90. Perçin, S. An integrated fuzzy SWARA and fuzzy AD approach for outsourcing provider selection. J. Manuf. Technol. Manag. 2019, 30, 531-552. [CrossRef] 
91. Ulutaş, A. Using of Fuzzy SWARA and Fuzzy ARAS Methods to Solve Supplier Selection Problem. In Advances in Business Strategy and Competitive Advantage; IGI Global: Hershey, PA, USA, 2019; pp. 136-148.

92. Liu, Y.; Wang, X.-K.; Wang, J.-Q.; Li, L.; Cheng, P.-F. Cloud model-based PROMETHEE method under 2D uncertain linguistic environment. J. Intell. Fuzzy Syst. 2020, 38, 4869-4887. [CrossRef]

93. Ghasemi, P.; Talebi, E. An Integrated FAHP-PROMETHEE Approach for Selecting the Best Flexible Manufacturing System. Eur. Online J. Nat. Soc. Sci. 2014, 3, 1137-1150.

94. Ghasemi, P.; Komijan, A.R. Decision Making Using PROMETHEE Method with Learning Visual PROMETHEE Software; Azad Islamic University: Tehran, Iran, 2015.

95. Qi, X.; Yu, X.-H.; Wang, L.; Liao, X.; Zhang, S. PROMETHEE for prioritized criteria. Soft Comput. 2019, 23, 11419-11432. [CrossRef]

96. Mamalis, S.A.; Kamenidou, I.; Pavlidis, S.; Xatziaggelou, A. Perceptions of Hospital Quality: A Case Study from Greece. In Advances in Panel Data Analysis in Applied Economic Research; Springer Science and Business Media LLC: Cham, Switzerland, 2020; pp. 403-410.

97. Gholami, M.; Keshtvarz Hesam Abadi, A.M.; Miladi, S.; Gholami, M. A systematic review of the factors affecting the growth of medical tourism in Iran. Int. J. Travel Med. Glob. Health 2020, 8, 1-12. [CrossRef]

98. Nikraftar, T.; Falahati, N. The Process of Developing an Innovative Medical Tourism Business in Iran. Iran. J. Econ. Stud. 2020, 8, 335-348.

99. Hawaldar, I.T.; Ullal, M.S.; Birau, R.; Spulbar, C.M. Trapping Fake Discounts as Drivers of Real Revenues and Their Impact on Consumer's Behavior in India: A Case Study. Sustainability 2019, 11, 4637. [CrossRef]

100. Lončarić, D.; Lončarić, D.; Marković, S. Health tourism, customer satisfaction and quality of life: The role of specialty hospitals. In Proceedings of the 3rd International Scientific Conference Tourism in Southern and Eastern Europe 2015 (ToSEE), Opatija, Croatia, 14-16 May 2015; Volume 3, pp. 159-173.

101. Kušen, E. Positioning medical tourism in the broader framework of health tourism. Turiz. Znan. Stručni Časopis 2011, 59, 95-99.

102. Lee, S.M.; Lee, D.; Kang, C.-Y. The impact of high-performance work systems in the health-care industry: Employee reactions, service quality, customer satisfaction, and customer loyalty. Serv. Ind. J. 2012, 32, 17-36. [CrossRef]

103. Rad, N.F.; Som, A.P.M.; Zainuddin, Y. Service Quality and Patients' Satisfaction in Medical Tourism. World Appl. Sci. J. 2010, 10, 24-30.

104. Connell, J.A.; Burgess, J. The influence of precarious employment on career development: The current situation in Australia. Educ. Train. 2006, 48, 493-507. [CrossRef]

105. Spulbar, C.; Ejaz, A.; Birau, R.; Trivedi, J. Sustainable Investing Based on Momentum Strategies in Emerging Stock Markets: A Case Study for Bombay Stock Exchange (BSE) of India. Sci. Ann. Econ. Bus. 2019, 66, 351-361. [CrossRef]

106. Mehdiabadi, A.; Tabatabeinasab, M.; Spulbar, C.; Yazdi, A.K.; Birau, R. Are We Ready for the Challenge of Banks 4.0? Designing a Roadmap for Banking Systems in Industry 4.0. Int. J. Financ. Stud. 2020, 8, 32. [CrossRef]

107. Gündoğdu, F.K.; Kahraman, C. A novel spherical fuzzy analytic hierarchy process and its renewable energy application. Soft Comput. 2020, 24, 4607-4621. [CrossRef]

108. Chang, T.-H. Fuzzy VIKOR method: A case study of the hospital service evaluation in Taiwan. Inf. Sci. 2014, $271,196-212$. [CrossRef] 